\title{
ALEKSANDAR MILOSAVLJEVIC PERIODONTAL TREATMENT STRATEGIES IN GENERAL DENTISTRY
}
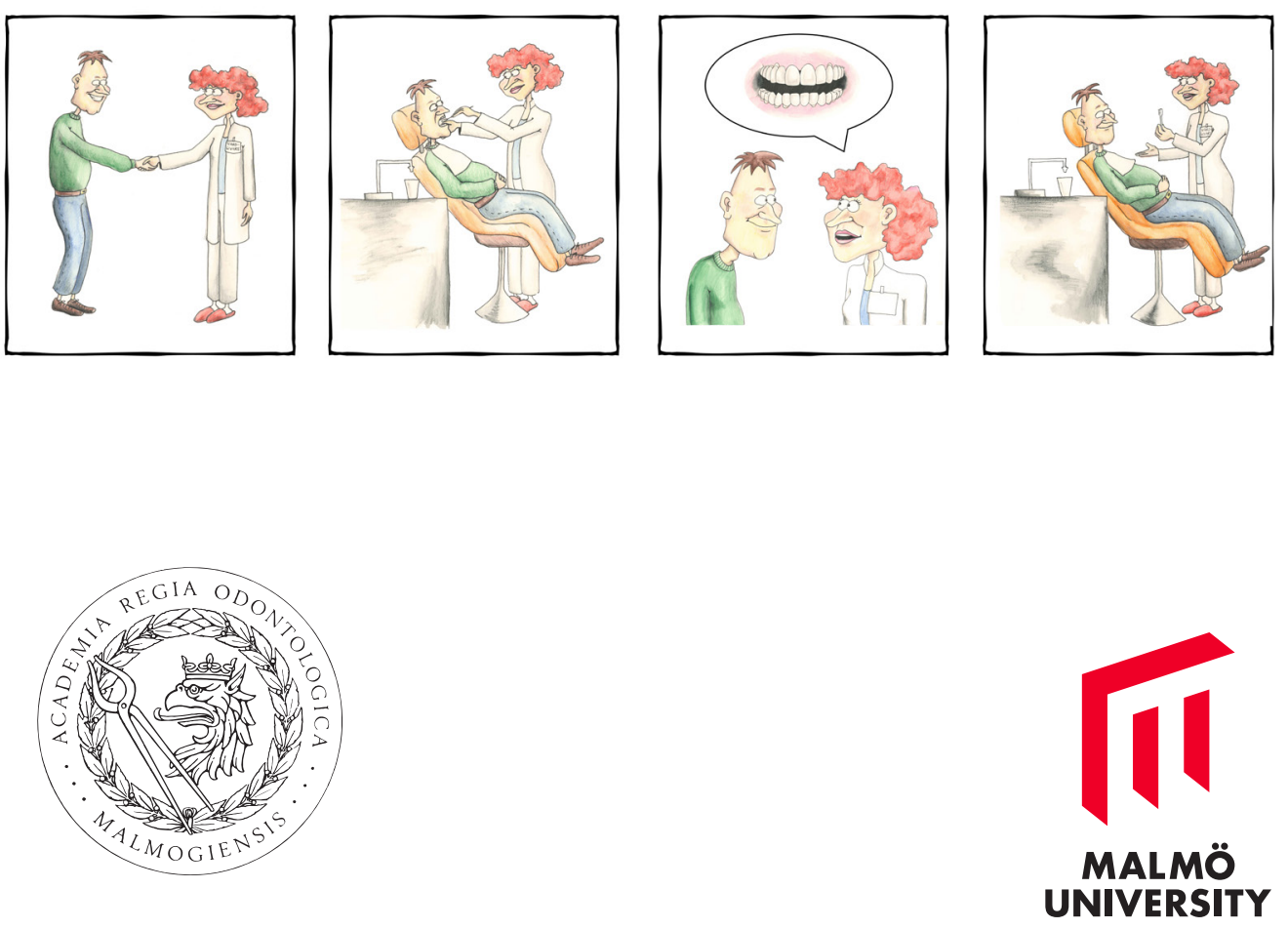

PERIODONTAL TREATMENT STRATEGIES IN GENERAL DENTISTRY 
Malmö University, Faculty of Odontology Doctoral Dissertation 2018

(C) Aleksandar Milosavljevic, 20 I 8

Cover illustration: Aleksandar Milosavljevic

ISBN 978-9I-7IO4-906-3 (print)

ISSN 978-9I-7I04-907-O (pdf)

Holmbergs, Malmö 2018 


\section{ALEKSANDAR MILOSAVLJEVIC PERIODONTAL TREATMENT STRATEGIES IN GENERAL DENTISTRY}

Malmö University, 2018 Faculty of Odontology Malmö, Sweden 
This publication is also available in electronic format at: www.mau.se/muep 
To my beloved family 



\section{CONTENTS}

LIST OF ARTICLES ............................................... 9

ABSTRACT .................................................. 11

POPULÄRVETENSKAPLIG SAMMANFATTNING (IN SWEDISH) ... 15

ABBREVIATIONS .............................................. 17

INTRODUCTION ................................................ 19

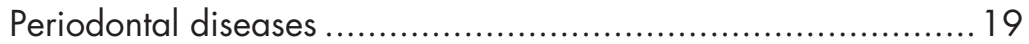

Diagnosis of periodontal diseases ................................... 21

Treatment of periodontal diseases .................................... 23

Periodontal risk and prognostic assessment ....................... 24

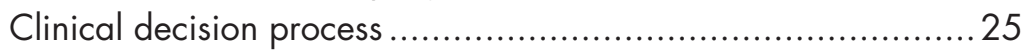

Clinical decision-making in dentistry ................................ 27

Clinical decision-making in periodontology .......................28

Quantitative and qualitative data collection methods...............29

The descriptive phenomenological psychological method......31

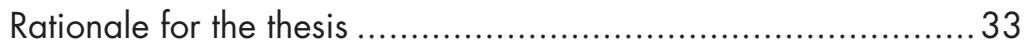

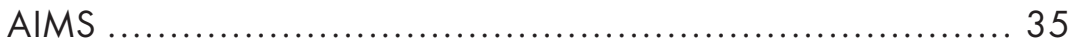

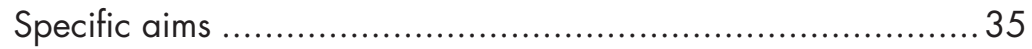

MATERIAL AND METHODS ................................ 37

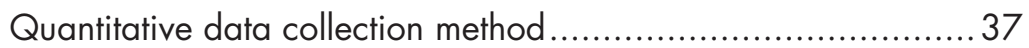

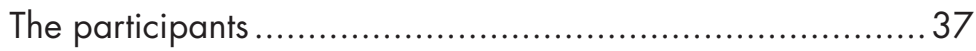

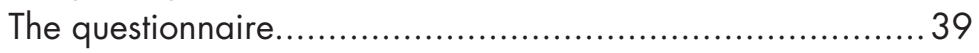

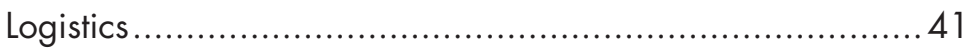

Theoretical framework ................................................ 43

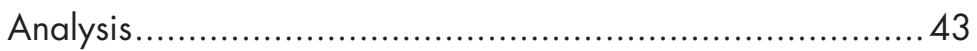

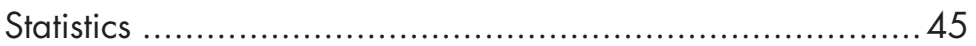

Qualitative data collection method.........................................45

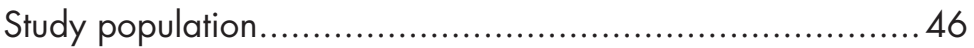

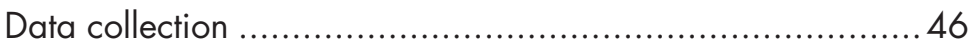

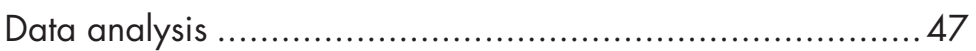




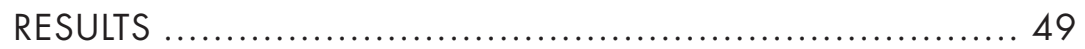

Quantitative data (Study I-IV)......................................... 49

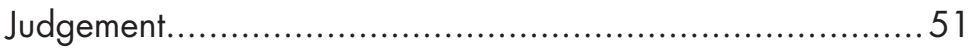

Treatment need and extent of treatment.............................5 1

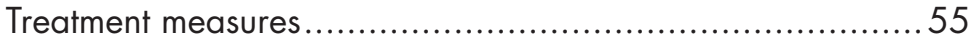

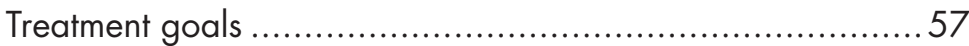

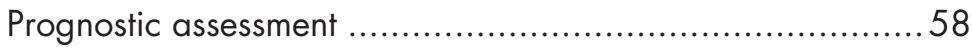

Qualitative data (Study V) ............................................... 61

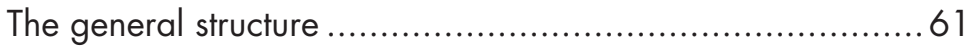

Constituent A: An established treatment routine...................62 62

Constituent B: Importance of oral hygiene .........................6 63

Constituent C: Self-awareness and motivation of the patient ..63

Constituent D: Support and doubt .................................6 63

Constituent E: Mechanical infection control ........................64 64

DISCUSSION ....................................................... 65

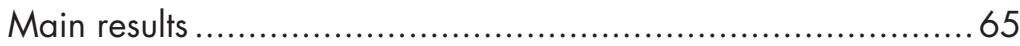

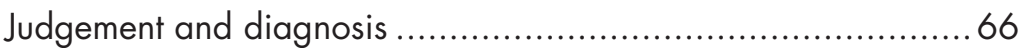

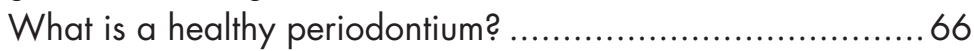

Distinguishing between gingivitis and periodontitis.............69

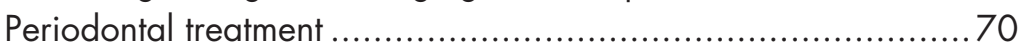

A standardised treatment - what does it mean? ..................70

A plaque-free patient................................................. 72

Learning environment impact on treatment decisions ........... 73

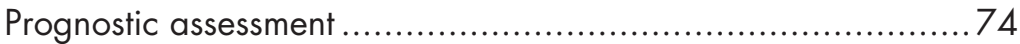

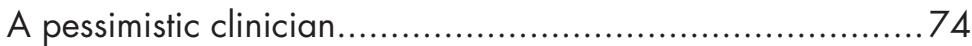

Judgement influencing the prognostic assessment ................ 75

Methodological considerations.........................................76

Representativeness of the sample and patient cases.............76

Validity and generalisability in DPPM .............................78

CONCLUSION ............................................... 81

FUTURE RESEARCH....................................... 83

ACKNOWLEDGMENTS ..................................... 85

REFERENCES ................................................ 89

APPENDIX 1 .................................................. 101

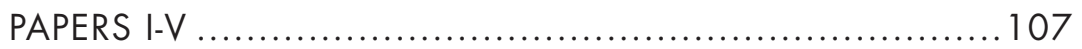




\section{LIST OF ARTICLES}

This thesis is based on the following articles, referred to in the text by their Roman numerals. All articles are reprinted with permission from the copyright holders and appended to the end of the thesis.

I. Different treatment strategies are applied to patients with the same periodontal status in general dentistry. Milosavljevic A, Götrick B, Hallström H, Jansson H, Knutsson K. Acta Odontol Scand. 2014;72:290-7.

II. Assessment of Prognosis and Periodontal Treatment Goals Among General Dental Practitioners and Dental Hygienists. Milosavljevic A, Götrick B, Hallström H, Stavropoulos A, Knutsson K. Oral Health Prev Dent. 2016;14:433441.

III. A questionnaire-based study evaluating differences between dental students in Paris (F) and Malmö (SE) regarding diagnosis and treatment decisions of patients with different severity levels of periodontal diseases. Milosavljevic A, Stavropoulos A, Descroix V, Götrick B. Eur J Dent Educ. 2018 Jan 8. doi: 10.1111/eje.12317. [Epub ahead of print]

IV. Diagnostic judgement and treatment decisions in periodontology by periodontists and general dental practitioners in Sweden - A questionnaire based study. Milosavljevic A, 
Stavropoulos A, Bertl K, Götrick B. Accepted for publication in Oral Health and Preventive Dentistry.

V. The lived experience of performing a periodontal treatment in the context of general dentistry. Milosavljevic A, Wolf E, Englander M, Stavropoulos A, Götrick B. Submitted to International Journal of Dental Hygiene.

\section{Contribution of the respondent}

The respondent has performed most of the work regarding planning, data collection, analysis of the data and writing the manuscripts of the articles. 


\section{ABSTRACT}

Periodontal diseases, such as gingivitis and chronic periodontitis, are infectious diseases that are common in the adult population. In Sweden, treatment is mostly provided in general dentistry by general dental practitioners (GDPs) and dental hygienists (DHs). The care chain also comprises periodontists since they act as consultants to the GDPs and DHs. Several studies have explored how clinicians judge, diagnose, and treat patients with different diseases but no previous study has explored how patients, with commonly occurring periodontal conditions in a population, are diagnosed and treated in general dentistry. Therefore the overall aim of the thesis was to study the treatment strategies applied by general dentistry clinicians to patients with common periodontal conditions. This thesis is based on five studies, where study I-IV are based on a questionnaire and conducted using a quantitative approach while study $\mathrm{V}$ is based on in-depth interviews and conducted using a qualitative approach.

The questionnaire in study I-IV comprised four simulated patient cases with different periodontal conditions. These four cases represent the periodontal status of the majority of middle-aged patients presented in a general dentistry practice: 1) Generalised bone loss but minimal signs of inflammation (well-maintained), 2) Generalised bone loss and signs of inflammation (periodontitis), 3) Negligible bone loss and minimal signs of inflammation (healthy), and 4) Negligible bone loss but with signs of inflammation (gingivitis). The clinicians who participated in the studies were asked to judge 
each patient case as healthy or diseased, propose a diagnosis, evaluate treatment needs, propose a treatment plan, and assess the prognosis.

In study I, GDPs and DHs were combined in one group as general dentistry clinicians (GDCs) and compared as to their judgement, proposed diagnosis and proposed treatment. Key findings: Three of the four patient cases was each judged as healthy by some GDCs and as diseased by others. The difference in judgement did not influence the GDCs' intention to treat or their proposed treatment measures but did influence the estimated number of treatment sessions.

In study II, GDCs were compared as to their prognostic assessment, treatment goals and estimation of treatment extent in terms of more or less treatment assigned to a given patient case in comparison to the other patient cases (healthy patient case excluded). Key finding: The majority of GDCs was in general pessimistic in their prognostic assessment and anticipated that all patient cases were to experience a deterioration of their periodontal condition. The most common treatment goal, irrespective of the patient case, was to improve oral health awareness. The periodontitis patient case was estimated to need the most treatment; slightly more than the gingivitis and the well-maintained patient cases where a similar treatment extent was estimated.

In Study III, dental students (DSs) from Paris (DSP) and Malmö (DSM) were compared to each other as to judgement, diagnosis, treatment plans, and prognostic assessment. This was done in order to discover if difference in educational background might influence DSs' treatment strategies. Key finding: The majority of both groups of DSs judged all the patient cases as diseased. DSPs proposed periodontitis as a diagnosis more readily and estimated a higher risk for disease progression in patient cases with no obvious bone loss (healthy and gingivitis patient cases). DSPs also recommended more treatment measures and estimated longer treatment time for all the patient cases than DSMs. 
In study IV, periodontists were primarily compared amongst each other and secondly to GDPs as to their judgement, diagnosis, proposed treatment plans, and prognostic assessment. Key findings: Both periodontists and GDPs varied in their judgement and proposed diagnosis. The difference in periodontists' judgement influenced their intention to treat and prognostic assessment. The GDPs intended to treat three out of four patient cases (except the periodontitis patient case) more often and were more pessimistic in their prognostic assessment of patient cases with negligible bone loss than the periodontists.

In Study V, the phenomenon of lived experience of performing a periodontal treatment in the context of general dentistry was described by analysing interviews from three different DHs using the descriptive phenomenological psychological method. Key finding: The periodontal treatment is perceived more as a standardised workflow than as an individually tailored treatment. The patients' oral hygiene and self-awareness are experienced as crucial parts while the mechanical infection control is perceived as successful but sometimes difficult to perform. The DHs are experiencing a need to be supportive of the patient but are sometimes doubtful of the patient's ability to achieve and maintain a positive change in oral health behaviour. 


\section{POPULÄRVETENSKAPLIG SAMMAN- FATTNING (IN SWEDISH)}

Det finns ett flertal sjukdomar som kan drabba tandens fäste till omkringliggande vävnad och dessa kallas gemensamt för parodontala sjukdomar (tandlossningssjukdomar). De vanligast förekommande parodontala sjukdomarna är gingivit och kronisk parodontit. Båda sjukdomarna orsakas av bakterier som ger upphov till en försvarsreaktion (inflammation) i mjukvävnaden kring tänderna. Gingivit innebär inflammation i tandköttet utan att tandens fäste till den omkringliggande mjukvävnaden och käkbenet har påverkats. Kronisk parodontit innebär att den inflammatoriska processen har resulterat i att tandens fäste har börjat brytas ner. Parodontala sjukdomar är vanliga och de behandlas huvudsakligen inom allmäntandvården. Behandlingen utgörs framför allt av åtgärder som syftar till att eliminera orsaken till inflammation genom att minska bakteriemängden på tandytorna.

Det övergripande målet med avhandlingen var att studera hur patienter med vanligt förekommande parodontala sjukdomar bedöms och behandlas i allmäntandvården. För att studera detta konstruerades en enkät, som fyra av avhandlingens fem delarbeten är baserade på. Med hjälp av enkäten undersöktes hur tandläkare, tandhygienister, tandläkarstudenter och specialisttandläkare bedömer patienter med olika parodontala sjukdomar och vilken behandling de anser att dessa patienter bör få. 
Resultaten visade att en och samma patient kunde bli bedömd som frisk av en behandlare och som sjuk av en annan behandlare. Denna bedömning påverkade både den föreslagna behandlingen och prognosbedömningen. Om en patient bedömdes som sjuk blev denne erbjuden mer behandling och tillskriven en sämre prognos än om samma patient bedömdes som frisk. Generellt sätt fick samtliga patienter, oavsett omfattning av parodontal sjukdom, en liknande behandling och risken för fortsatt sjukdomsutveckling bedömdes vara någorlunda lika. Utöver studierna som utgick från en enkät gjordes en studie som baserades på djupintervjuer av tandhygienister. Resultaten visade att behandling av parodontal sjukdom ofta upplevs som en rutin som följer ett på förhand bestämt innehåll.

Sammanfattningsvis kan sägas att patienter inom allmäntandvården tycks fä $i$ stort sett samma behandling för parodontal sjukdom, oavsett hur de ser ut i munnen. Behandlingen individanpassas inte vilket kan leda till att vissa patienter underbehandlas och andra överbehandlas. Detta kan medföra att tandvarrdens resurser inte utnyttjas effektivt. Vidare kan samma patient bedömas som frisk av en behandlare och som sjuk av en annan behandlare och denna bedömning påverkar det behandlingsförslag som patienten erbjuds. Det finns därför ett behov av att klargöra vad som är parodontalt friskt och vad som är parodontalt sjukt för att skapa en bättre samstämmighet bland tandläkare och tandhygienister när det gäller såväl bedömning som behandling. 


\section{ABBREVIATIONS}

$\begin{array}{ll}\text { AB } & \text { Antibiotics } \\ \text { AL } & \text { Attachment loss } \\ \text { BOP } & \text { Bleeding on probing } \\ \text { CAL } & \text { Clinical attachment loss } \\ \text { CDC-AAP } & \text { Centers for Disease Control and Prevention and the } \\ & \text { American Academy of Periodontology } \\ \text { CEJ } & \text { Cementoenamel junction } \\ \text { CP } & \text { Chronic periodontitis } \\ \text { DH } & \text { Dental hygienist } \\ \text { DPPM } & \text { Descriptive phenomenological psychological method } \\ \text { DS } & \text { Dental student } \\ \text { DSM } & \text { Dental student from Malmö University, Faculty of } \\ & \text { Odontology } \\ \text { DSP } & \text { Dental student from Université Paris Diderot, Dentis- } \\ & \text { try UFR } \\ \text { EFP } & \text { European Federation of Periodontology } \\ \text { GDC } & \text { General dentistry clinician } \\ \text { GDP } & \text { General dental practitioner } \\ \text { OH } & \text { Oral hygiene } \\ \text { PC } & \text { Patient case } \\ \text { PD } & \text { Probing depth } \\ \text { PLI } & \text { Full-mouth plaque score } \\ \text { SRP } & \text { Scaling and root planing } \\ \text { VAS } & \text { Visual analogue scale } \\ \end{array}$




\section{INTRODUCTION}

For the sake of clarity, in this thesis the term treatment strategies do not only refer to treatment decisions. Instead, it encompasses the entire decision-making chain involved in the encounter between a patient and a clinician, i.e., judgement of the patient's periodontal status and prognostic assessment are also covered by the term treatment strategies.

\section{Periodontal diseases}

The most common periodontal diseases are plaque-induced gingivitis (from hereon referred to as gingivitis) and chronic periodontitis (Armitage, 2004b). Prevalence of gingivitis ranges from 8 to $33 \%$ while periodontitis ranges from 1 to $81 \%$, the range depending on the age group studied (Hugoson et al., 2008). Gingivitis is described as gingival inflammation without loss of connective tissue attachment; the lesion is confined to the gingiva, and presence of bacterial plaque on the tooth surface is a prerequisite (Mariotti, 1999). Chronic periodontitis, on the other hand, is defined as "an infectious disease resulting in inflammation within the supporting tissues of the teeth, progressive attachment and bone loss" (Lindhe et al., 1999). If chronic periodontitis is left untreated, it could lead to loss of teeth, which in turn could result in reduced oral healthrelated quality of life by impairing mastication and altering the food intake of an individual (Gotfredsen and Walls, 2007). Furthermore, gingival disease is a precursor to periodontitis but not all gingival lesions result in attachment and bone loss (Lang et al., 2009, Schatzle et al., 2003a). 
Historically, instances of periodontal diseases are documented as far back as ancient times. Approximately 5000 years ago, Chinese practitioners of medicine recognised inflammation of gingiva by tooth mobility and foul breath (Gold, 1995). Moreover, Hippocrates discussed etiology and pathogenesis of bleeding or rotten gums during the period of classical antiquity but the first intellectual discussion of periodontal pathology and therapy was undertaken by Pierre Fauchard in the publication Le chirurgien dentist (Löe, 1993). A more systematic approach to the description of periodontal diseases was established as late as the end of the $19^{\text {th }}$ century when the disease was predominantly classified by its clinical characteristics. However, the causes of the disease were still unknown and only speculated upon (Armitage, 2002). The first attempt to classify the periodontal diseases by cause was carried out in the first half of the $20^{\text {th }}$ century by Gottlieb (Gottlieb, 1946) and Orban (Orban, 1942). Orban classified the periodontal diseases in five ways: inflammatory, degenerative, atrophic, hypertrophic and periodontal trauma. One of the most interesting aspects of this classification was that the degenerative form of the disease was thought to be a non-inflammatory and unstoppable process with tooth loss as the endpoint (Armitage, 2014). These classifications were readily used until it was showed that gingivitis was caused by microorganisms and hence disclosed that infection plays an important etiological role for periodontal diseases (Loe et al., 1965). Extensive research in the field of periodontology followed and some landmark papers further explained the infection and host response interplay (Page and Schroeder, 1976) and suggested that specific microorganisms play a crucial role in the infection (Socransky, 1977). These, and many other research studies led to the establishment of the "generic" term periodontitis which, by the end the 1980s, was classified into different entities (Armitage, 2002). This classification from 1989 was later revised for several reasons, one being the lack of a category for gingival diseases. In 1999, an international workshop was organised and the present classification system for periodontal diseases was established which include both gingival diseases and periodontitis (Armitage, 1999). 
This brief historical outline shows that the definition of periodontal diseases has been prone to changes during the last century. Thus, the diagnostic criteria for gingivitis and periodontitis have also been subject to revision and have changed into the form that is used in clinical praxis today. However, since the definitions have been changed regularly, this might mean that the periodontal community is not in agreement on the definitions and therefore they have not been fully accepted and are infrequently implemented in general dentistry.

\section{Diagnosis of periodontal diseases}

During a patient's initial visit to a dental practice, the periodontal examination is important since it is the foundation for diagnosis and planning of treatment. The examination often starts with medical history followed by gentle periodontal probing in order to assess inflammation and presence and/or extent of destruction of the periodontal tissues. Inflammation is most often assessed by bleeding on probing (BOP) while the destruction of the periodontium, i.e., attachment loss, can be hinted by the measurement of probing depth (PD) or determined by measuring clinical attachment loss (CAL). In addition to this, furcation involvements and mobility could also indicate destruction of the periodontal tissues (Armitage, 2004a).

BOP is a widely used and fairly accurate diagnostic method when determining inflammation in a periodontal pocket. This method is mostly used dichotomously, i.e., showing presence or non-presence of inflammation in the periodontal soft tissues (Greenstein, 1984) with high sensitivity and specificity (De Souza et al., 2003). On the other hand the method is weak when it comes to indicating disease activity in terms of progressive attachment loss but is a strong indicator of periodontal stability meaning that one could presume that no breakdown of the supporting tissues is occurring when bleeding is absent (Lang et al., 1990, Lang et al., 1986).

PD is a common method in dental practice to detect attachment loss around teeth since it measures the depth of the sulcus (distance between gingival margin and the tip of the probe). In healthy cir- 
cumstances, the depth of the sulcus is $1-3 \mathrm{~mm}$, but in diseased sites a higher PD value is commonly noted. However, a high PD value does not necessarily mean that attachment loss has occurred since swelling of the gingival tissues could result in a higher PD value (formation of pseudopocket). On the other hand, a normal PD value could indeed be present at sites which have formerly experienced attachment loss but are uninflamed at the moment (Wolf and Lamster, 2011). Additionally, this method also has some limitations since it tends to overestimate the depth of the true (histological) pocket in inflamed sites while it underestimates the depth in healthy sites (Fowler et al., 1982). A more objective measure of attachment loss can be obtained by determining CAL (distance between cementoenamel junction and the tip of the probe), even though the method is mostly used in research rather than daily clinical practice (Tugnait et al., 2000). Another common method of examining attachment loss is by using radiographs (Jeffcoat and Reddy, 2000). In periodontology, radiographs are an aid to detect horizontal and vertical bone loss, furcation involvements, calculus, overhangs of fillings, and other pathologies of the dental and periodontal tissues (Tugnait et al., 2000). When examining horizontal bone loss, the distance between cementoenamel junction (CEJ) and the horizontal bone level is measured. In healthy circumstances, this distance is, in most cases, below $2 \mathrm{~mm}$ on bitewing radiographs. If the distance between CEJ and the horizontal bone level exceeds $2 \mathrm{~mm}$, one could consider it as evidence of bone loss (Hausmann et al., 1991). Moreover, all common radiographic methods (periapical, bitewing, panoramic) underestimate the horizontal bone loss and differences arise in accuracy depending on which radiographic method is employed (Åkesson et al., 1992). However, although these clinical and radiographic observational methods measure attachment loss they do not show if the periodontal destruction is progressive or at a stable level. In order to see if progression has occurred one has to perform two observations with the same method but at different times (Baelum and Lopez, 2003, Jeffcoat and Reddy, 2000).

All of the above-mentioned findings are collected on a toothlevel basis but in order to arrive at a periodontal diagnosis one has 
to combine all findings and propose a diagnosis on a patient level (Armitage, 2004b). In this particular situation, the definitions of gingivitis and chronic periodontitis play a pivotal role and guide the clinician when proposing a diagnosis. Therefore when proposing gingivitis as a diagnosis, findings such as BOP must be present, while findings such as CAL or bone loss must be absent (Caton et al., 1999). If periodontitis is proposed as a diagnosis, then both $\mathrm{BOP}$ and findings indicating progressive attachment loss should be present (Lindhe et al., 1999). Moreover, in order to distinguish between chronic and aggressive periodontitis one has to additionally assess factors such as: general health, rate of attachment loss and familial aggregation (Lang et al., 1999). Lastly, only if a patient lacks all of the findings indicating gingival inflammation and attachment loss can the patient be considered as periodontally healthy by definition (Mariotti and Hefti, 2015).

\section{Treatment of periodontal diseases}

Periodontal treatment can be divided into five different phases: systemic, acute, cause-related, surgical corrective, and maintenance (Dentino et al., 2013). While the first two phases are important in general, the bulk of the periodontal treatment (i.e. treatment of gingivitis and chronic periodontitis) lies in the last three phases.

In the treatment of gingivitis the goal is primarily to reduce the inflammation in the gingival tissues, however the treatment of gingivitis could also be specified as a strategy to prevent development of periodontitis (Chapple et al., 2015). The treatment of gingivitis is cause-related and focused on removing and controlling the plaque (Lang, 2014). Therefore it is important to motivate the patient to efficient oral health behaviours (Stenman et al., 2009) but also give proper instructions since it has a positive effect on the reduction of inflammation (Jönsson et al., 2009). Additionally, if patients use powered toothbrushes (Van der Weijden and Slot, 2015) and inter-dental cleaning devices (Sälzer et al., 2015) they will reduce gingivitis more effectively. Furthermore, in order to reach the goal of reduced inflammation one also has to perform professional mechanical tooth cleaning and scaling and root planing (SRP) where applicable (Axelsson et al., 2004). 
Considering chronic periodontitis, treatment is not only focused on reducing supragingival plaque but also on controlling the subgingival microflora by SRP (Cobb, 2002). Most patients with mild to moderate periodontitis show a favourable response to nonsurgical periodontal treatment (Greenstein, 2000) since it has been shown that even relatively deep pockets can be successfully treated with this conservative approach (Badersten et al., 1981). The positive effects of the SRP are closely related to the self-performed oral hygiene which has to be optimal in order to maintain a healthy subgingival microflora (Sbordone et al., 1990). However, in patients exhibiting pockets with PD $>6 \mathrm{~mm}$ surgical treatment is advocated since the attachment gain and PD reduction is significantly greater in comparison to non-surgical treatment (Heitz-Mayfield et al., 2002) with the prerequisite of good oral hygiene (Nyman et al., 1977) and an established plan of maintenance phase prior to the surgical treatment (Becker et al., 1984). The maintenance phase of the periodontal treatment is vital since it has been shown that a long-lasting maintenance program can prevent recurrence of periodontal diseases and tooth mortality (Axelsson et al., 2004). Furthermore, supportive periodontal treatment during the maintenance phase has to be based on the patient risk-profile and individualised to the patient (Renvert and Persson, 2004).

Hence, in the case of treatment of patients with common periodontal diseases (gingivitis and chronic periodontitis) it is clear that the remedies for these diseases are similar, however they should be individually tailored to the patients' actual treatment need in order to obtain successful results.

\section{Periodontal risk and prognostic assessment}

Risk assessment is performed on healthy patients and deals with the probability of developing a disease based on certain risk factors, risk indicators, and risk predictors. Risk factors are plausible casual agents for the disease that are preceding the development of the disease in longitudinal studies. Risk indicators are also plausible casual agents for development of the disease but have only been confirmed in cross-sectional studies. Risk predictors on the other hand are not casual agents but have been associated with the dis- 
ease in both cross-sectional and longitudinal studies (Pihlstrom, $2001 \mathrm{~b}$ ). There are several risk factors for development of periodontal disease, such as poorly controlled diabetes and smoking, which can alter the susceptibility or resistance of an individual to the disease (Genco and Borgnakke, 2013). Susceptibility to periodontitis is an important factor to acknowledge since it is well-known that some individuals never experience attachment loss although lacking preventive measures or dental treatment in their habitat (Löe et al., 1986).

Prognostic assessment on the other hand is a prediction of the course of an existing disease based on prognostic factors (Beck, 1998). A prognosis can be assigned both on tooth level and on patient level since there are local factors that affect specific teeth (e.g., tooth anatomy) or general factors that are affecting the whole dentition (e.g., diabetes) (Kwok and Caton, 2007). Risk factors for developing periodontitis, such as smoking, could also be attributed to the prognostic assessment (Beck, 1998), but local factors are equally important. Several local factors have been shown to have an impact on further progression of the disease. Patients with residual PD $>5 \mathrm{~mm}$, after cause-related therapy, are more likely to experience further clinical attachment loss (Renvert and Persson, 2002). This correlation has also been seen in other studies where local factors (plaque accumulation, BOP, baseline attachment level, PD, recession, mobility) contributes to the risk of new attachment loss (Haffajee et al., 1991, Nieri et al., 2002) and are accurate in predicting prognosis at 5-8 years after initial assessment (McGuire and Nunn, 1996).

Hence, risk- and/or prognostic assessments are important for several reasons. They guide the clinician in the decision-making process (Faggion et al., 2007), help improve patient outcomes (Douglass, 2006) and contribute to the planning of maintenance care of treated patients (Lang and Tonetti, 2003).

\section{Clinical decision process}

Clinical decision making is a complex process with several influencing variables, such as diagnostic and therapeutic uncertainties, patient preferences, personal values, cost (Hunink et al., 2014) and 
clinicians' knowledge base and capacities. In a simplified form, it could be divided into five consecutive steps: 1) The initial patientdoctor meeting (examination) where gathering of data (findings) occurs. 2) Analysis of findings with the help of prior knowledge of different disease profiles to propose a diagnosis. 3) Evaluation of the certainty of the proposed diagnosis. If uncertainty exists, additional data gathering procedures are conducted (regressing to step 1). If no uncertainty is present one progresses to treatment decision. 4) Treatment proposal based on prior knowledge of the prognosis of the disease in cases of treatment or no treatment. 5) Finally, results from treatment evaluation are recorded (Wulff and Gøtzsche, 2000). In the steps regarding diagnosis (step 2-3) and treatment decision (step 4) there are several factors influencing the decisions a clinician makes which could contribute to the variability in treatment decision between clinicians.

Differences in treatment decisions stem from two main sources: perceptual variation and judgmental variation. Perceptual variation means that clinicians perceive a condition differently, i.e., they disagree amongst each other on what they see. It means that the same patient could be diagnosed differently and thus different treatment decisions are made. Judgmental variation means that the clinicians agree on what they perceive or see, but they disagree on how the specific condition should be treated (Kay and Nuttall, 1995a). However, perception is not always a matter of how we perceive things with our senses, it could also be related to how we perceive information we have obtained from a clinical examination, e.g., clinical data from a journal chart. According to the fuzzy trace theory, people rely on the gist of information (bottom-line meaning of the information), which is created by their subjective interpretation of the information. This is in turn based on their experience, education, emotions, culture, worldview, and level of development. Their judgements and decisions are affected by how they understand the given information, rather than the facts they are presented with (Reyna, 2008). Furthermore, uncertainties in diagnostics and treatment could also influence our judgement and the decisions we make, e.g., validity and reliability of diagnostic methods or the lack of evidence for a certain treatment (Hunink et al., 2014). 
The above-mentioned decision-making process could be described as a sequential processing model, which means that the clinicians always make a diagnostic judgement first, and subsequently, based on the diagnostic judgement and factors relevant to treatment, make a treatment decision. On the other hand, it has been shown that this decision-making process is not always utilised in clinical situations. Instead, in some cases, the clinicians do not make distinctions between diagnostic and therapeutic decisions. They utilise independent processing which means that factors pertinent to diagnosis and treatment are simultaneously processed in order to arrive at diagnostic judgement and treatment decisions separately from each other (Sorum et al., 2002).

Lastly, the previous factors are pertinent to the clinicians, but there are other factors that also influence the treatment decisions. Patient preferences are important in the treatment planning since the patients might have opinions on certain treatment decisions and treatment choice (Kay and Nuttall, 1995a). In this shared medical decision process the patients are considering treatment outcome probabilities together with the clinicians in order to reach a decision based on mutual agreement (Frosch and Kaplan, 1999). Environmental factors such as incidence of a disease in a certain area where the treatment is provided might also influence the clinicians in their decision making (Kay and Nuttall, 1995b).

\section{Clinical decision-making in dentistry}

Differences in judgements and treatment decisions exist both in the field of medicine and the field of dentistry, even when consensus exists on how a certain condition should be treated (Knutsson et al., 2005). It has been shown that dentists from different countries vary in their restorative threshold of caries lesions even though they make similar diagnostic judgements (Kay and Locker, 1996). Although one could presume that environment plays a role in the variation between dentists from different countries, differences are also seen between dentists within the same country (Baraba et al., 2010). Similarly, variation exists between dental students. Students tend to disagree in their assessment of caries lesions (Maupomé and Sheiham, 1997) and have different treatment thresholds for 
proximal caries owing to the fact that they have different educational background (Bervian et al., 2009).

The educational background is important in the clinicians' decision-making process. Previous studies have shown that specialists in endodontics obtain a greater agreement in endodontic diagnosis and treatment decisions in comparison to dentists and dental students. Furthermore, they tend to choose a conservative treatment approach and treat existing teeth in contrast to dentists and dental students who are more prone to extract teeth with endodontic problems (McCaul et al., 2001, Bigras et al., 2008, Çiçek et al., 2016). This highlights the impact of experience and expertise on decision making. On the other hand, experience might not always change the treatment attitude of the dentist, e.g., dentists continue to remove third-molars prophylactically although evidence has emerged implying that this intervention is not cost-effective (Knutsson et al., 2001). Furthermore, expertise in a field does not always mean that a better agreement is established among the experts in that particular field. When oral surgeons perceive a risk of future pathology in disease-free third molars they disagree to the same extent as regular dentists (Kostopoulou et al., 2000).

\section{Clinical decision-making in periodontology}

The above-mentioned variations in diagnostics, treatment and prognostic assessment have also been observed within the field of periodontology. Two questionnaire studies, involving dentists in USA and Australia, showed that patients with the same periodontal condition were diagnosed differently, i.e., the variation in diagnosis between clinicians could range from healthy to severe periodontitis for a single patient case. However, the potential effect of dentists' diagnostic variability on treatment decisions was not analysed in these particular studies, only speculated upon (Martin et al., 2013, Bailey et al., 2016). On the other hand, studies exploring both diagnostic judgements and treatment decision, although separately, have been conducted on dental students from different dental schools. These studies showed that the diagnostic and treatment agreement between students, both within and between the dental schools, were low (John et al., 2013, Lane et al., 2015). Moreover, 
clinical instructors also vary in their interpretation of clinical findings, periodontal diagnosis, and treatment planning (Lanning et al., 2005) but on the other hand a substantial agreement could be seen between periodontists when discriminating between patient cases with chronic and aggressive periodontitis (Oshman et al., 2016). However, when periodontists assess the risk for worsening of periodontal conditions differences were apparent between specialists with different educational background (Persson et al., 2003).

Even though previous studies have addressed decision-making processes in periodontology there is no study, to the best of my knowledge, that have explored: 1) the correlation between diagnostic judgement and treatment decisions in periodontology 2) compared European dental students in diagnostic judgement and treatment decisions for patients with different periodontal conditions 3) compared periodontists' and general dentists' treatment strategies for patients with common periodontal conditions. Furthermore, the only research methods used in previous studies are comprising quantitative data collected by questionnaires. No qualitative approaches have been used when exploring decision-making processes in periodontology; such an approach might help us foster a deeper understanding of the reasons behind clinicians' treatment strategies.

\section{Quantitative and qualitative data collection methods}

In principle, there are two categories of collected data in research: quantitative and qualitative. The most commonly used distinction between these two is framed in terms of qualitative data comprising words and quantitative data comprising numbers (Creswell, 2009), i.e., qualitative research questions deal with "what something is like" while quantitative research questions are based on "how much" and "how many" (Englander, 2012). Furthermore, the goal of research comprising qualitative data is to understand social phenomena in their natural setting with the emphasis on participants' meaning, experiences, and views (Pope and Mays, 1995). Research comprising quantitative data is mostly based in an experimental setting focusing on causality between independent and dependent variables (Englander, 2012). Therefore, the research ques- 
tions are of outmost importance when choosing the method for a research study as it defines the foundation of the object one aims to study (Morse, 1991). Other fundamental differences are based on the reasoning behind the methods. The quantitative data collection methods mainly employ deductive reasoning meaning that the point of departure is the available theory on the topic that a hypothesis is based on and tested. On the other hand, some qualitative data collection methods commonly implement inductive reasoning, where the observations precedes the hypothesis with the endpoint of formulating a theory (Creswell, 2009, Pope and Mays, 1995). While there are many differences between the methods, they also have similarities. Both methods are empirical and rely on observations. Although the observations are differently designed, they have the same goals which are to describe the data, construct explanatory arguments, and speculate on the reasons for the outcome of the observation (Sechrest and Sidani, 1995). However, one has to keep in mind that there are methods that do not rely on observation through sensory perception of empirical objects (Giorgi, 2009), and this means that an inductive or deductive reasoning is not feasible.

Understandably one could view these methods as very different and opposite to each other, but they could actually be viewed as an interactive continuum (Newman and Ridenour, 1998). These methods could be seen as complementary (Sechrest and Sidani, 1995), where both methods are needed to gain a more complete understanding of a researched phenomenon (Onwuegbuzie and Leech, 2005). Research comprising qualitative data could be used as a preparatory for a study comprising quantitative data or it can be used as a supplement to quantitative data in order to validate the findings or to enable a deeper understanding (Pope and Mays, 1995). Therefore, if the two methods are combined one could obtain methodological pluralism which is a characteristic of good research (Sechrest and Sidani, 1995). This is especially true for the field of dentistry since we are not only interested in what people do, we are also interested in peoples' thoughts, feelings, attitudes, perceptions, and preferences. Therefore, by combining these two research methods one could obtain a greater understanding of a 
variety of issues important for dentistry (Stewart et al., 2008) and a deeper understanding of periodontal treatment could be achieved.

The descriptive phenomenological psychological method One method, which can be used to obtain a deeper understanding of periodontal treatment, is the descriptive phenomenological psychological method (DPPM). This method allows us to study the meaning of a certain phenomenon as a lived experienced by an individual. These meanings can only appear in somebody's consciousness since they are experiential and not considered as real as they do not exist in space and time. Instead they are considered to be ir-real because they depend on consciousness to exist but are not able to be touched e.g. dreams. Hence, these objects are not empirical and would not be possible to perceive with physical senses. Instead, they can be intuited which means that one can only be present to all of the concrete manifestations of the phenomenon and describe these carefully (Giorgi, 2009). Furthermore, meanings are subjective by their nature to the individual experiencing them but since these experiences can be shared with others, they can be grasped objectively. They could also be seen as a determinate relationship between an act of consciousness and its object (Giorgi, $2005)$, i.e., the intention is to study the intentionality rather than casual relationships in order to identify the essential structure of the phenomenon (Figure 1) (Englander, 2012, Englander, 2016). 


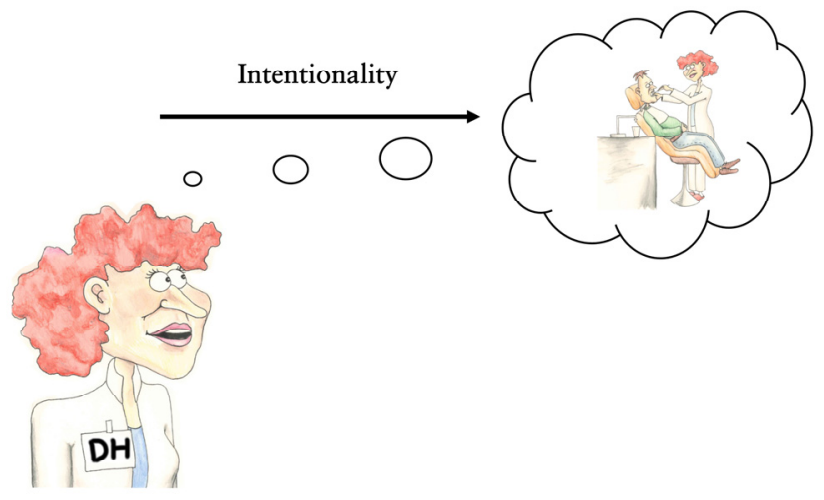

Figure 1: Intentionality represents directedness of mind to objects. DH: dental hygienist.

In order to arrive at the essential structure of a phenomenon in an objective way, one has to adhere to important scientific criteria for obtaining knowledge. These criteria imply that the research is systematic, methodical, general, and critical. Systematic means that the knowledge that is produced should not be random but instead patterned and ordered. Methodical means that the knowledge is gained through a method that is accessible to the community, general means that the knowledge obtained could be applied to other similar situations, and critical means that the knowledge is challenged through systematic procedures in the research method. The DPPM meets these scientific criteria. It is a rigorous and precise method that allows for systematic presentation and critical reflections of the obtained knowledge. The method is available for other researchers to use and since the descriptions of the experiences are obtained from other people, the knowledge can be generalised to similar context in which the phenomenon appears (Giorgi, 2009, Giorgi, 1997, Applebaum, 2012).

Therefore, by using this method one could achieve a valid knowledge and a more profound understanding of the phenomenon of interest. In this context, the description of the lived experience of performing a periodontal treatment in general dentistry could yield a better understanding of how periodontal treatment is experienced by clinicians and not only how it is conducted. 


\section{Rationale for the thesis}

In this introduction, some aspects important to this thesis have been acknowledged. It has been explained that gingivitis and chronic periodontitis are commonly occurring in the population and that the diagnostics and treatment of these diseases has been the subject of much research. However, there is limited information on how this knowledge has been transferred and implemented in a general dentistry setting, which is where most patients receive periodontal care. Furthermore, it has been explained how different categories of clinicians (students, dentists, specialists) vary in their clinical decision process. However, to the best of my knowledge, no previous study has investigated how patients with commonly occurring periodontal conditions in a population are diagnosed and treated by clinicians affiliated with general dentistry. Additionally, the correlation between clinicians' diagnostic judgement and treatment decisions has not been previously studied. Lastly, the possibilities when combining quantitative and qualitative data with the purpose of reaching a more profound understanding of a researchable problem have been explored, but there is no previous research that have utilised this approach when studying decision-making processes in periodontology. It is not only interesting to strive to understand how clinicians form their treatment strategies, the experience of conducting a treatment is equally interesting. Therefore, this thesis aims to address all the abovementioned aspects in order to receive a better understanding of how clinicians, who are affiliated with general dentistry in different ways, diagnose and treat patients with the most common periodontal diseases. 


\section{AIMS}

The overall aim of the thesis is to study the treatment strategies of clinicians affiliated with general dentistry, as applied on patients with common periodontal conditions.

\section{Specific aims}

- To study general dental practitioners' and dental hygienists' treatment strategies for patients with common periodontal conditions (Study I).

- To evaluate general dental practitioners' and dental hygienists' assessment of prognosis, suggested treatment goals, and estimated amount of treatment in patients with varying degrees of severity of periodontal disease (Study II).

- To evaluate differences between last-year dental students at different dental schools with regard to their judgement and clinical decision making within periodontology (Study III).

- To evaluate whether the periodontists, in their role as consultants to general dental practitioners, a) are consistent in their judgement and treatment decisions, and b) vary significantly compared to general dental practitioners in judgement and treatment decisions regarding patients with common periodontal conditions (Study IV). 
- To describe what characterises the lived experience of performing a periodontal treatment in general dentistry in order to obtain a deeper understanding of the clinicians' rationale for periodontal treatment (Study V). 


\section{MATERIAL AND METHODS}

\section{Quantitative data collection method}

Studies I-IV are based on a questionnaire, which included four different patient cases with questions concerning diagnostic judgement, treatment decisions, and prognostic assessment of each patient case. In total there were three similar versions of the questionnaire, one version for studies I and II and a separate version for each of the remaining studies (III-IV). The participants invited to complete the questionnaires consisted of general dental practitioners (GDP) and dental hygienists (DH), dental students (DS) and periodontists. The GDPs and DHs will be referred to as general dentistry clinicians (GDCs) when presented together.

The participants

All GDCs ( $\mathrm{n}=127)$ employed by the public dental service in the Swedish county of Halland were invited to participate in study I and II. For the third study (III) all last-year DSs from Universite Paris Diderot, Dentistry UFR (DSP) $(\mathrm{n}=96)$ and Malmö University, Faculty of Odontology (DSM) ( $\mathrm{n}=45)$ were invited to participate. For study IV the target group was all licensed periodontists in Sweden who were members of the Swedish Society of Periodontology and for whom a valid (functioning) e-mail address could be obtained ( $\mathrm{n}=86)$. Additionally, the previous sample of GDPs $(\mathrm{n}=77)$ from the first two studies (I-II) was included in the total sample for study IV (Figure 2). According to the advisory opinion of the Regional Ethical Board at Lund University (LU-317/2006) this type of questionnaire-based studies do not need ethical approval. 


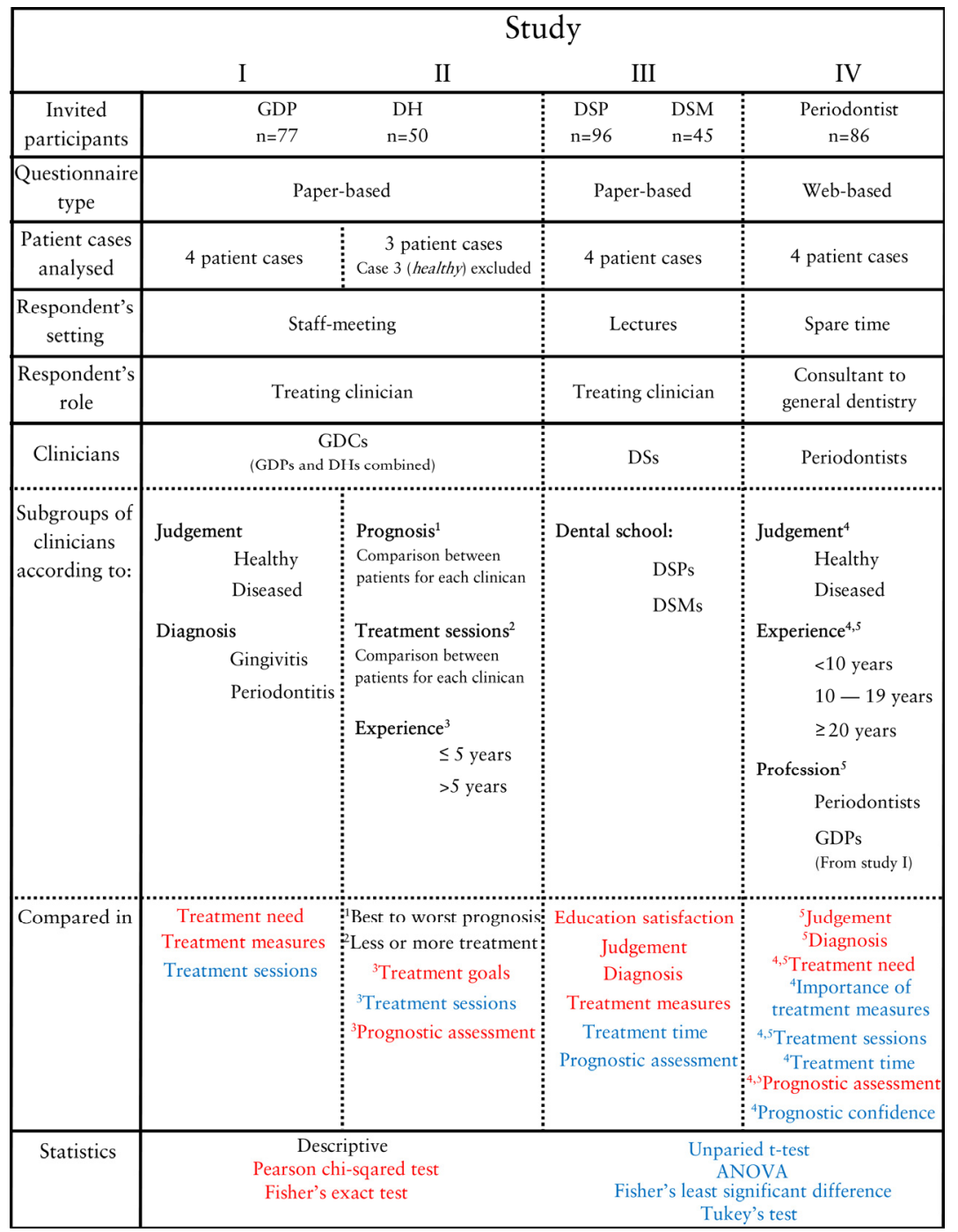

Figure 2. Flowchart of study I-IV. General dental practitioner (GDP), dental hygienist (DH), dental student (DS), dental student from Paris (DSP), dental student from Malmö (DSM), general dentistry clinician (GDC). 
Medical history

Male
48 years

Systemically healthy

No medications

No tobacco use

Well-maintained

Patient case 1
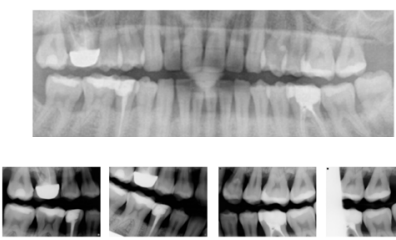

Periodontal status

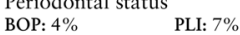

$\begin{array}{ll}\text { BOP: } 4 \% & \text { PLI: } 7 \% \\ \text { PD }=4 \mathrm{~mm}: 5 \text { sites } & \text { PD }=5 \mathrm{~mm}: 0 \text { sites }\end{array}$

$\mathrm{PD} \geq 6 \mathrm{~mm}$ : 0 sites Boneloss: $1 / 3$ of root length
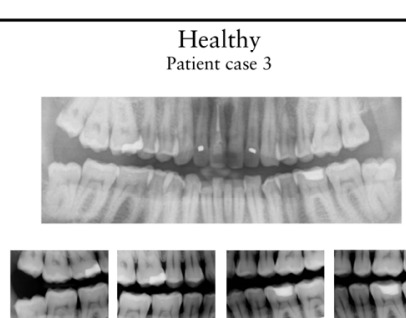

Periodontal status

BOP: $5 \% \quad$ PLI: $5 \%$

$\mathrm{PD}=4 \mathrm{~mm}: 5$ sites $\quad \mathrm{PD}=5 \mathrm{~mm}: 0$ sites

PD $\geq 6 \mathrm{~mm}: 0$ sites Boneloss: Negligible
Dental history

New patient

Lived abroad for 10 years

Received regular dental care

Last treatment 1 year ago

No restorative treatment last 15 years

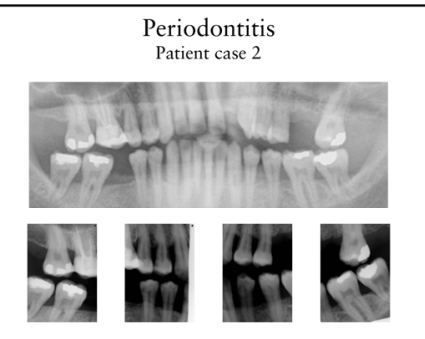

Periodontal status

BOP: $37 \% \quad$ PLI: $37 \%$

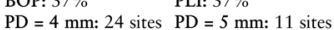

$\mathrm{PD} \geq 6 \mathrm{~mm}: 0$ sites Boneloss: $1 / 3$ of root length

Gingivitis

Patient case 4
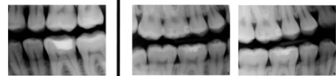

netion yos

Periodontal status

$\begin{array}{ll}\text { POP: } 38 \% & \text { PLI: } 30 \%\end{array}$

$\mathrm{PD}=4 \mathrm{~mm}: 44$ sites $\mathrm{PD}=5 \mathrm{~mm}: 0$ sites

PD $\geq 6 \mathrm{~mm}: 0$ sites Boneloss: Negligible

Figure 3. Patient history, periodontal status, panoramic and

bitewing images of each patient case. BOP: number of sites (ex-

pressed in \%) with bleeding on probing, PLI: plaque index, PD: probing depth

The questionnaire

The questionnaires contained four simulated patient cases with different periodontal conditions (Figure 3). The patient cases represented the majority $(>85 \%$ ) of middle-aged patients presented in a general dentistry practice (Hugoson et al., 2008). The patient cases are described as follows: Patient case 1) generalised alveolar bone 
loss but minimal ( $\mathrm{BOP} \leq 5 \%$ ) clinical signs of inflammation (i.e., well-maintained); patient case 2) generalised bone loss and clinical signs of inflammation (i.e., periodontitis); patient case 3) negligible alveolar bone loss and minimal (BOP $\leq 5 \%$ ) clinical signs of inflammation (i.e., healthy); patient case 4) negligible alveolar bone loss but with clinical signs of inflammation (i.e., gingivitis).

All four patient cases were presented in the same manner (Appendix 1) including the information most often obtained during a full periodontal examination: patient history, description of the periodontal status by a full-mouth periodontal chart, and four bitewings (in this study one panoramic image and a written radiologist's report were also included). The patient cases had the same medical history (i.e., a 48-year-old, healthy, non-smoking male) and a similar dental history (e.g. having lived abroad for the last ten years, regular dental care) but varied in their periodontal status described by their full-mouth bleeding score, PD, full-mouth plaque score (PLI), and marginal bone level (Figure 3).

The first part of the questionnaires comprised questions aiming to obtain demographic characteristics of the respondents. Questions regarding gender and age were included in all studies but additional questions (e.g., professional experience) were adapted to each study's target sample. A question regarding satisfaction with the periodontal education during undergraduate studies were only given to the DSs. For each patient case, the questionnaires included questions on diagnostic judgement, treatment, and prognosis. All participants were asked to judge each patient case as healthy or diseased and propose a diagnosis if the patient case was judged as diseased. Furthermore, they were asked to select (GDCs, DSs) or rate the importance of (periodontists) different treatment measures, estimate the extent of treatment by selecting number of treatment sessions (GDC, periodontists) or approximate the treatment time in hours (DSs, periodontists). Lastly, they were asked to assess the prognosis of each patient case, however they were asked to do so in different ways. The GDCs assessed the prognosis through openended questions; the DSs did so by estimating the risk of tooth loss by a $100 \mathrm{~mm}$ visual analogue scale (VAS) and periodontists through predetermined answer options while also rating the confidence in 
their own prognostic assessment. There were also questions that were not presented to all the participating groups. GDCs and periodontists could specifically state if each of the patient cases needed treatment while GDCs could also propose treatment goals (openended question). The GDCs' answers to the open-ended questions concerning treatment goals and prognostic assessment were scrutinised during the analysis in order to group the answers in specific categories. Four separate categories were obtained for treatment goals: a) improve oral health awareness, b) reduction of inflammation and PD, c) plaque and calculus removal, d) periodontal status maintenance/prevention of progression. Prognostic assessment also included four categories: a) unchanged, b) uncertain, c) increased inflammation, no bone loss, d) worsening in terms of bone loss. Concerning treatment goals, each GDC's answer could be categorized in one or more groups in contrast to prognostic assessment where only one answer fitted to one category. The categorisation of GDPs' answers for prognostic assessment was modified in study IV. The worsening category was subdivided into two categories: increased bone loss and tooth loss. The uncertain category was excluded in order to facilitate comparison between GDPs and periodontists. For a detailed explanation of the questions and answer options for each participating group, see table 1 .

\section{Logistics}

The first version of the questionnaire was distributed to the GDCs. Initially, the questionnaire and the purpose of the study was presented to each clinical supervisor in the public dental service in Halland during a brief meeting. At this point the paper questionnaires, together with pre-paid envelopes, were distributed to the clinical supervisors who in turn handed them out to their employees at a later occasion. Time was allocated for each clinic to complete the questionnaires during a staff meeting and every questionnaire was coded in order to find clinics with non-respondents. After two weeks a reminder was sent by e-mail to the clinical supervisors whose employees had not returned the questionnaires. 
Table 1: Demographic and case specific questions included in each version of the questionnaire together with answer options. $\mathrm{OH}$ : oral hygiene, CP: chronic periodontitis, VAS: visual analogue scale, AB: antibiotics

\begin{tabular}{|c|c|c|c|}
\hline \multirow[b]{2}{*}{ Demographic questions } & \multicolumn{3}{|c|}{ Answer options } \\
\hline & $\begin{array}{l}\text { General dental } \\
\text { clinicians }\end{array}$ & $\begin{array}{c}\text { Dental } \\
\text { students }\end{array}$ & Periodontists \\
\hline Gender? & Female/Male & Female/Male & Female/Male \\
\hline Age? & No. of years & No. of years & No. of years \\
\hline Professional experience? & No. of years & --------------- & No. of years \\
\hline $\begin{array}{l}\text { Do you consider that you have received } \\
\text { enough training in periodontology during } \\
\text { your undergraduate education? }\end{array}$ & -------------- & Yes/No & --------------- \\
\hline \multicolumn{4}{|l|}{ Case specific questions } \\
\hline $\begin{array}{l}\text { According to your opinion is the patient } \\
\text { gingivally and/or periodontally diseased? }\end{array}$ & Yes/No & Yes/No & Yes/No \\
\hline $\begin{array}{l}\text { If you consider the patient as diseased, } \\
\text { which diagnosis do you propose? }\end{array}$ & $\begin{array}{l}\text { - Gingivitis } \\
\text { - CP } \\
\text { - Other: (state) }\end{array}$ & $\begin{array}{l}\text { - Gingivitis } \\
\text { - CP } \\
\text { - Other: (state) }\end{array}$ & $\begin{array}{l}\text { - Gingivitis } \\
\text { - CP } \\
\text { - Other: (state) }\end{array}$ \\
\hline Does the patient require any treatment? & Yes/No & 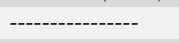 & Yes/No \\
\hline $\begin{array}{l}\text { GDC and DS version: } \\
\text { Which of the following treatment- } \\
\text { measures do you consider the patient to } \\
\text { need? }\end{array}$ & $\begin{array}{l}\text {-Disease info. } \\
\text {-OH instr. } \\
\text {-Polishing } \\
\text {-Scaling } \\
\text {-Re-evaluation }\end{array}$ & $\begin{array}{l}\text {-Disease info. } \\
\text {-OH instr. } \\
\text {-Polishing } \\
\text {-Scaling } \\
\text {-Re-evaluation }\end{array}$ & $\begin{array}{l}\text {-Disease info. } \\
\text {-OH instr. } \\
\text {-Polishing } \\
\text {-Scaling } \\
\text {-Re-evaluation }\end{array}$ \\
\hline $\begin{array}{l}\text { Periodontist version: } \\
\text { How important do you rate the following } \\
\text { treatment measures for this patient? } \\
\text { (100mm VAS for each treatment measure, } \\
0=\text { Not important, } 100=\text { Very important ) }\end{array}$ & -Perio. surg. & $\begin{array}{l}\text {-Perio. surg. } \\
\text {-Local AB } \\
\text {-Systemic AB } \\
\text {-Other: (state) }\end{array}$ & $\begin{array}{l}\text {-Perio. surg. } \\
\text {-Supportive } \\
\text { treatment }\end{array}$ \\
\hline $\begin{array}{l}\text { How many treatment sessions - beyond } \\
\text { the examination - are required? }\end{array}$ & $\begin{array}{l}\text { No. of sessions } \\
\text { min:0, max:5 }\end{array}$ & 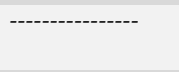 & $\begin{array}{l}\text { No. of sessions } \\
\text { min:0, max:20 }\end{array}$ \\
\hline $\begin{array}{l}\text { Reasonable total treatment time }(\mathrm{h}) \text {, Inde- } \\
\text { pendently of whom performs the treat- } \\
\text { ment? }\end{array}$ & & $\begin{array}{l}\text { No. of hours } \\
\text { freely written }\end{array}$ & $\begin{array}{l}\text { No. of hours } \\
\text { min:0, max: } 20\end{array}$ \\
\hline What is the goal with the treatment? & Freely written & - & - \\
\hline $\begin{array}{l}\text { GDC and periodontist version: } \\
\text { If the patient doesn't receive any treatment } \\
\text { in the next ten years, what changes should } \\
\text { be expected regarding his periodontal } \\
\text { health? }\end{array}$ & Freely written & $\begin{array}{l}0=\text { no risk } \\
100=\text { high risk }\end{array}$ & $\begin{array}{l}\text {-Unchanged } \\
\text {-Increased } \\
\text { inflammation, } \\
\text { no bone loss } \\
\text {-Increased } \\
\text { bone loss }\end{array}$ \\
\hline $\begin{array}{l}\text { DS version: } \\
\text { If the patient does not receive any treat- } \\
\text { ment at all in the future, how high do you } \\
\text { assess the risk to be that the patient loses } \\
\text { one/several teeth? (100mm VAS) }\end{array}$ & & & -Tooth loss \\
\hline $\begin{array}{l}\text { How confident are you about your prog- } \\
\text { nosis? (100mm VAS) }\end{array}$ & ------- & --------------- & $\begin{array}{l}0=\text { not conf. } \\
100=\text { very conf. }\end{array}$ \\
\hline
\end{tabular}


The second version of the questionnaire was distributed to all DSPs and DSMs. The students received the questionnaires on paper during compulsory lectures while being informed about the purpose of the study. The questionnaires were collected directly after being filled out.

The third version of the questionnaire was distributed to all participating periodontists in digital form. An invitation with a direct link to the questionnaire was sent out by e-mail and at the same time informing the participants of the study purpose and that they were supposed to respond as consultants to the general dentistry sector. A reminder was sent out on three different occasions (two, four, and six weeks after the initial invitation). All versions of the questionnaire were filled out anonymously.

\section{Theoretical framework}

The purpose of the questionnaire was to explore if the participants would vary in their diagnostic judgement and treatment decisions for patients with different, but common, periodontal conditions. Variation in treatment was studied from several perspectives and was based primarily on the theory that variation in treatment stem from two different sources of variation: perceptual variations and judgmental variation (Kay and Nuttall, 1995a). Perceptual variation means that if individuals interpret the same conditions differently the result would be that the treatment decision will vary because the individuals think they see different levels of disease. Judgmental variation means that individuals could agree about what they see and how it is judged but disagree about how the condition should be treated. Other aspects such as professional experience, place of education, and dental profession were also accounted for when the variation in diagnostic judgement and treatment was studied.

\section{Analysis}

In the first two studies (I-II), the GDPs and DHs were combined in one group (GDC). This group of GDCs was then divided depending primarily on their judgement of each patient case as healthy or diseased in study I. The participants who judged a patient case as 
diseased were further divided into two groups based on their proposed diagnosis i.e. one group consisted of GDCs who proposed gingivitis as a diagnosis and the other group consisted of GDCs who proposed periodontitis as a diagnosis for the same patient case. These divisions were done in order to analyse if differences in diagnostic judgement would influence subsequent treatment decisions in terms of anticipated treatment need, treatment measures, and treatment sessions.

In study II one patient case was excluded (healthy) and only GDCs who judged the remaining patient cases as diseased were accounted for in the analysis regarding prognostic assessment. In this study, the same GDCs as in study I were divided depending on their professional experience. Inexperienced $(\leq 5$ years) and experienced ( $>5$ years) GDCs were compared to each other as to their prognostic assessment, proposed treatment goals, and estimated number of treatment sessions. Furthermore, an additional comparison was made between GDCs. This comparison was done in the same way for prognostic assessment and proposed treatment sessions. Each GDC was placed in two different groups. The first group was based on how they assessed the prognosis of one patient case in relation to the two other patient cases (best to worst prognosis). Obviously, if the prognosis was assessed as "uncertain" in any given patient case, the GDC had to be excluded. The second group was based on their estimation of the number of treatment sessions for one patient case in relation to the two other patient cases in terms of more or less treatment.

In study III the participating DSs were divided according to their place of education (Paris or Malmö). Thereafter, they were compared as to their satisfaction with their periodontal education at their respective university, their judgement of patient cases as healthy or diseased, proposed diagnosis and treatment measures, estimation of treatment time, and prognostic assessment for each patient case.

Periodontist who participated in study IV were primarily compared among each other in two different and separate ways. First, they were divided according to their professional experience into three groups: least experienced $(<10$ years), moderately experi- 
enced (10 - 19 years), and very experienced ( $\geq 20$ years) and compared to each other for all the questions in the questionnaire. Secondly, the periodontists were divided according to their judgement of each patient case as healthy or diseased and compared to each other in all questions except for judgement and proposed diagnosis. Moreover, the periodontists were also compared to the GDPs from the first two studies regarding judgement, proposed diagnosis, anticipated treatment need, estimated number of treatment sessions, and prognostic assessment. In this study the number of treatment sessions was adjusted from " 0 " to " 1 " in the analysis for respondents who anticipated a need for treatment but on the other hand estimated " 0 " treatment sessions. This was done because there was no option in the questionnaires to divide the first visit into two parts if a respondent intended to treat a certain patient case during the same scheduled appointment as the examination.

\section{Statistics}

The same statistical tests were used in all four studies. Pearson Chisquared and Fisher's exact test were used when participants were compared concerning questions regarding judgement, proposed diagnosis, anticipated treatment need, selected treatment measures, treatment goals, prognostic assessment (study II, IV) and satisfaction with periodontal education (study III). Unpaired t-test, ANOVA, Fisher's least significant difference, and Tukey's test compared differences in questions regarding rated importance of treatment measures, treatment sessions, treatment time, prognostic assessment (study III) and confidence in one's own prognostic assessment. SPSS Version 20.0-23.0 (SPSS Inc., Chicago, IL, USA) was used for all the calculations in study I, II and IV and GraphPad QuickCalcs for study III. The level of significance was set at $p \leq$ 0.05 in all tests.

\section{Qualitative data collection method}

The method (DPPM) consists of three steps: 1) obtain a description from research participants of a situation in which the phenomenon was experienced, 2) adopt a critical and reflective attitude by setting aside all existential claims of the research object (such as as- 
sumptions, previous knowledge, theories, and preconceptions) in order to approach the study object as a phenomenon (i.e., reducing it to its intentionality), 3) clarify and describe a general meaning structure of the phenomenon (that rest on intentional relations) by using the method of eidetic variations. Eidetic variations mean that the researcher has to be critical when varying what comes through as essential in the raw data in order to discover a general structure that is constituted on the basis of intentional relations (Giorgi, 2009).

\section{Study population}

Three clinically active DHs from both public and private general dentistry in the county of Skåne, Sweden, were chosen as the target sample in order to obtain descriptions of situations where the phenomenon had been experienced. This group was purposively sampled as they treat patients with periodontal disease on a daily basis. Hence, the inclusion criteria for the DHs were that they were currently performing periodontal treatment on a regular basis and had a recent memory of a situation in which they had performed the treatment process. Moreover, the specific DHs were strategically selected as they, in addition to fulfilling the inclusion criteria, also had diverse demographic characteristics in terms of age, gender, professional experience, place of education, and employer setting. The aim was to obtain descriptions from individuals with different backgrounds and professional experiences (Table 2). This sampling strategy was conducted so that the focus was on the phenomenon and its relation to a context (Englander, 2012). The study was approved by the Regional Ethical Board at Lund University, Lund, Sweden (LU-752/2013).

Table 2. Participant (dental hygienists) demographics

\begin{tabular}{llllll} 
Participant & Age & Gender & $\begin{array}{l}\text { Professional } \\
\text { experience }\end{array}$ & Place of education & Employer \\
\hline 1 & 38 & Female & 13 years & Malmö University & Public \\
2 & 35 & Male & 11 years & Kristianstad University & Public \\
3 & 55 & Female & 31 years & Malmö University & Private \\
\hline
\end{tabular}




\section{Data collection}

Two separate meetings were held between the interviewer (AM) and each of the three participants. During the first meeting, the participants were informed about the study aim, signed a consent form and were asked to mentally review a situation where they had performed a periodontal treatment on a patient. The second meeting (in-depth semi-structured interview) was scheduled for approximately a week after the first meeting.

The second meeting was structured around the question in which the participants were asked to describe, in as much detail as possible, a situation where they had performed a periodontal treatment on a patient. The participants independently chose a situation to recall and describe. During the interview, the participants could freely describe the situations and the interviewer only asked for clarification and a more detailed description when this was needed. Three in-depth semi-structured interviews were conducted in the above manner. The interviews lasted between 38 to 64 minutes. The interviews were documented using a digital sound recorder and transcribed verbatim.

\section{Data analysis}

The analysis of the interview material followed four consecutive methodological steps. In the first step, each transcribed interview was read several times in order to get a sense of the whole in terms of the overall relationship between the lived experience and the context.

In the second step, the transcribed interview was divided into so-called meaning units. This means that the interview was broken down into manageable parts. This step was epistemically consistent with phenomenological qualitative inquiry in that the researcher adopted the phenomenological psychological reduction (i.e., bracketing one's own presumptions of the research object to avoid making theoretical interpretations of the data) and was mindful of the specific phenomenon being investigated. This was done first and foremost in order to render the analysis more manageable and to facilitate easier access to parts of the interview when comparing the obtained results at the end with the original data in the interviews. 
In the third step, a repeated transformation of the raw data was made from each meaning unit. The purpose was to critically distinguish and describe the precise psychological meaning of each meaning unit and to identify the phenomenon's constituents (i.e., bearing elements). Therefore, the psychological dimension of the lived experience of performing a periodontal treatment described in each meaning unit had to be highlighted and the raw data had to be expressed in a secure way, which means that the expression was straightforward and descriptive. All data was accounted for, meaning that nothing was added or removed during the transformation process. Bracketing the existential index of the phenomenon, it enabled the researcher to describe the intentionality present in the data, i.e., the intentional, psychological relations connected to the lived experience of the phenomenon. Furthermore, during the transformation process the method of eidetic variation was utilised. To guide this methodological process, the researcher was asking the following question when approaching each meaning unit: "What does this particular meaning unit tell me about the lived experience of performing a periodontal treatment?". The written transformation of each meaning unit was critically varied several times until the most precise answer to the above question was found. At the end of this step, a series of transformed meaning units for each interview was obtained.

In the fourth step, all transformed meaning units from all three interviews were inter-correlated to each other and their interdependence was described using the phenomenological methodology of eidetic variations and the phenomenological psychological reduction. Lastly, the general structure of the phenomenon was described disclosing the interdependent relations of the constituents. 


\section{RESULTS}

\section{Quantitative data (Study I-IV)}

The response rate varied for each group of clinicians. The highest response rate $(94 \%)$ was obtained among GDPs and DHs as a group (GDC) where a total of 120 clinicians responded. DSs responded to a slighter less degree; $84 \%$ of the DSPs and $80 \%$ of the DSMs handed in a completed questionnaire. The periodontists had the lowest, albeit still high, response rate with $77 \%$. The mean age, mean professional experience (excluding DSs), and percentage of females for each participating group can be seen in table 3. Furthermore, a significantly $(p<0.05)$ higher number of DSMs stated that they had received sufficient teaching in periodontology $(91 \%)$ in comparison to DSPs $(61 \%)$.

Table 3. Demographics of participants in the questionnaire study

\begin{tabular}{lcccc} 
Participant & $\begin{array}{c}\text { Number of } \\
\text { respondents }\end{array}$ & $\begin{array}{c}\text { Mean age } \\
\text { (range) }\end{array}$ & $\begin{array}{c}\text { Mean professional } \\
\text { experience (range) }\end{array}$ & $\begin{array}{c}\text { Percentage } \\
\text { of females }\end{array}$ \\
\hline GDP & 74 & 45.4 years (24-70) & 17.2 years (0-41) & 62 \\
DH & 46 & 47.9 years (25-65) & 15.5 years (2-30) & 100 \\
\hline DSP & 81 & 24.6 years (22-36) & - & 58 \\
DSM & 36 & 26.0 years (23-34) & - & 67 \\
\hline Periodontist & 66 & 53.3 years (33-73) & 14.5 years $(0-36)$ & 50 \\
\hline
\end{tabular}


Table 4. Percentage of all general dentistry clinicians (GDC), general dental practitioners (GDP), dental students from Paris (DSP), dental students from Malmö (DSM), and periodontists, who judged each patient case (PC) as diseased and diagnosed either gingivitis or periodontitis. ${ }^{\dagger}$ Valid diagnoses are missing for some participants. ${ }^{\alpha}$ Other diagnoses were also proposed by dental students. * Significant difference $(p<0.05$.) between DSP and DSM.

\begin{tabular}{|c|c|c|c|c|}
\hline \multirow[t]{3}{*}{ Patient case } & \multirow[t]{3}{*}{ Participant } & \multirow{3}{*}{$\begin{array}{c}\text { Judgement } \\
\text { Diseased } \\
\%\end{array}$} & \multicolumn{2}{|c|}{ Diagnosis } \\
\hline & & & Gingivitis & Periodontitis \\
\hline & & & $\%$ & $\%$ \\
\hline \multirow{5}{*}{$\begin{array}{l}\text { Well-maintained } \\
\text { (PC 1) }\end{array}$} & GDC† & 80.0 & 8.3 & 70.8 \\
\hline & GDP & 79.7 & 6.7 & 73.0 \\
\hline & $\mathrm{DSP}^{\alpha}$ & 93.8 & 11.1 & 81.5 \\
\hline & $\mathrm{DSM}^{\alpha}$ & 100.0 & 11.1 & 80.6 \\
\hline & Periodontist & 78.8 & 7.6 & 71.2 \\
\hline \multirow{5}{*}{$\begin{array}{l}\text { Periodontitis } \\
\text { (PC 2) }\end{array}$} & GDC & 100.0 & 0 & 100.0 \\
\hline & GDP & 100.0 & 0 & 100.0 \\
\hline & DSP & 100.0 & 0 & 100.0 \\
\hline & DSM & 100.0 & 0 & 100.0 \\
\hline & Periodontist $†$ & 98.5 & 0 & 95.5 \\
\hline \multirow{5}{*}{$\begin{array}{l}\text { Healthy } \\
\text { (PC 3) }\end{array}$} & GDC $†$ & 41.7 & 32.5 & 8.3 \\
\hline & GDP† & 47.3 & 36.5 & 9.5 \\
\hline & DSP & 70.4 & $32.1^{*}$ & $38.3^{*}$ \\
\hline & DSM & 75.0 & 61.1 & 13.9 \\
\hline & Periodontist & 60.6 & 48.5 & 12.1 \\
\hline \multirow{5}{*}{$\begin{array}{l}\text { Gingivitis } \\
\text { (PC 4) }\end{array}$} & GDC & 90.0 & 75.0 & 15.0 \\
\hline & GDP & 93.2 & 78.4 & 14.8 \\
\hline & DSP & 97.5 & $53.7^{*}$ & $43.8^{*}$ \\
\hline & DSM & 97.2 & 91.7 & 5.5 \\
\hline & Periodontist & 89.4 & 81.8 & 7.6 \\
\hline
\end{tabular}




\section{Judgement}

Within all groups of participating clinicians, a variation in judgement of patient cases' periodontal conditions as healthy or diseased was seen in three out of the four patient cases. The patient case with the most severe periodontal condition, i.e., evident bone loss and general inflammation (periodontitis), was judged as disease by nearly all clinicians $(>98 \%)$ while the widest variation in judgement was seen in the healthy patient case (negligible bone loss and minimal signs of inflammation). Moreover, the well-maintained (evident bone loss and limited inflammation) and the gingivitis (negligible alveolar bone loss and general inflammation) patient cases were judged as diseased by the majority of all clinicians (Table 4).

Regarding the given diagnoses (after judging a patient case as diseased), a similar variation among the groups of clinicians was seen. The well-maintained and the periodontitis patient cases were diagnosed with periodontitis by most clinicians while the healthy and the gingivitis patient cases were in most cases diagnosed with gingivitis. Differences in the given diagnosis between groups of clinicians were only seen between the dental schools; a significantly higher number of DSPs diagnosed periodontitis in the healthy and the gingivitis patient cases in comparison to DSMs (Table 4).

\section{Treatment need and extent of treatment}

The group of respondents consisting of GDCs was uniform in their anticipation of a patient's treatment need in all the patient cases. Almost all GDCs proposed treatment for the well-maintained, periodontitis and gingivitis patient cases and $93 \%$ for the healthy patient case. Regarding periodontists, almost all agreed that the periodontitis patient case needed periodontal treatment and the vast majority had the same opinion concerning the well-maintained and gingivitis patient cases. However, the largest disagreement was seen within the periodontist group regarding the healthy patient case where $61 \%$ of the periodontists anticipated a treatment need. Furthermore, when periodontists and GDPs were compared, a significantly higher number of GDPs anticipated a treatment need in all patient cases except in the periodontitis patient case (Table 5). 
Table 5. Percentage of all general dentistry clinicians (GDC), general dental practitioners (GDP) and periodontists who anticipated a treatment need in each patient case. Average number of treatment sessions (GDC, GDP, periodontists) and average treatment time (DSP, DSM, periodontists) are presented. PC: patient case. * Significant difference $\left(p<0.05\right.$.) between GDPs and periodontists. ${ }^{*}$ Significant difference $(p<0.05$.) between DSP and DSM. Cl: confidence interval.

\begin{tabular}{|c|c|c|c|c|}
\hline \multirow[t]{3}{*}{ Patient case } & \multirow[t]{3}{*}{ Participant } & \multicolumn{3}{|c|}{ Treatment } \\
\hline & & Need & Sessions & Time (h) \\
\hline & & $\%$ & Mean $(95 \% \mathrm{CI})$ & Mean $(95 \% \mathrm{CI})$ \\
\hline \multirow{5}{*}{$\begin{array}{l}\text { Well-maintained } \\
\text { (PC 1) }\end{array}$} & GDC & 97.5 & $1.65(1.45,1.85)$ & - \\
\hline & GDP & $95.9^{*}$ & $1.94(1.70,2.18)$ & - \\
\hline & DSP & - & - & $2.92(2.72,3.12)^{\sharp}$ \\
\hline & DSM & - & - & $1.25(1.12,1.38)$ \\
\hline & Periodontist & 83.0 & $2.25(1.88,2.62)$ & $1.93(1.58,2.28)$ \\
\hline \multirow{5}{*}{$\begin{array}{l}\text { Periodontitis } \\
\text { (PC 2) }\end{array}$} & GDC & 100.0 & $3.04(2.84,3,24)$ & - \\
\hline & GDP & 100.0 & $3.20(2.95,3.45)^{*}$ & - \\
\hline & DSP & - & - & $4.97(4.70,5.24)^{¥}$ \\
\hline & DSM & - & - & $2.75(2.58,2.92)$ \\
\hline & Periodontist & 98.5 & $4.23(3.81,4.65)$ & $3.95(3.45,4.45)$ \\
\hline \multirow{5}{*}{$\begin{array}{l}\text { Healthy } \\
\text { (PC 3) }\end{array}$} & GDC & 92.5 & $0.67(0.52,0.83)$ & - \\
\hline & GDP & $93.2^{*}$ & $1.22(1.10,1.34)$ & - \\
\hline & DSP & - & - & $2.03(1.85,2.21)^{\sharp}$ \\
\hline & DSM & - & - & $0.73(0.63,0.83)$ \\
\hline & Periodontist & 60.6 & $1.47(1.24,1.7)$ & $1.15(0.86,1.44)$ \\
\hline \multirow{5}{*}{$\begin{array}{l}\text { Gingivitis } \\
\text { (PC 4) }\end{array}$} & GDC & 99.2 & $1.93(1.75,2.11)$ & - \\
\hline & GDP & $98.6^{*}$ & $2.07(1.85,2.29)^{*}$ & - \\
\hline & DSP & - & - & $3.21(2.96,3.46)^{7}$ \\
\hline & DSM & - & - & $1.40(1.27,1.53)$ \\
\hline & Periodontist & 89.4 & $2.44(2.15,2.73)$ & $2.17(1.84,2.5)$ \\
\hline
\end{tabular}


Regarding treatment sessions and treatment time, all clinicians estimated the periodontitis patient case to need the highest amount of treatment and the healthy patient case to need the lowest amount. The well-maintained and the gingivitis patient cases were estimated to need approximately the same amount of treatment, a bit more than the healthy patient case. In study II (concerning GDCs), a comparison of the number of treatment sessions needed for the various patient cases (healthy patient case excluded) in relation to each other was made. The largest fraction of GDCs (39\%) considered that the well-maintained and gingivitis patient cases would need the same number of treatment sessions, while the periodontitis patient case was estimated to require more sessions. A lower number of GDCs $(21 \%)$ estimated that the same number of treatment sessions would be needed for the gingivitis and periodontitis patient cases but more than the well-maintained patient case. A similar number of GDCs (17\%) considered the well-maintained patient case to have the least treatment need, followed by the gingivitis patient case, and then the periodontitis patient case which was estimated to need the most treatment. In study III, regarding DSs, a significant difference in estimated treatment time was seen between the dental schools; DSPs proposed significantly more time needed in all patient cases compared to DSMs. When periodontists were compared to the GDPs, the periodontists estimated significantly more treatment sessions for the periodontitis and gingivitis patient cases (Table 5).

\section{Influence of judgement on treatment}

A comparison was also made regarding the anticipated treatment need and estimated number of treatment sessions between clinicians (among GDCs and periodontists separately) who judged or diagnosed the same patient case differently. In three out of four patient cases (except the periodontitis patient case), those GDCs who judged the patient cases as diseased estimated a higher number of treatment sessions than those GDPs who judged the same patient cases as healthy (Figure 4). In the well-maintained patient case the GDCs' estimated number of treatment sessions was also higher if the given diagnosis was periodontitis instead of gingivitis, while 


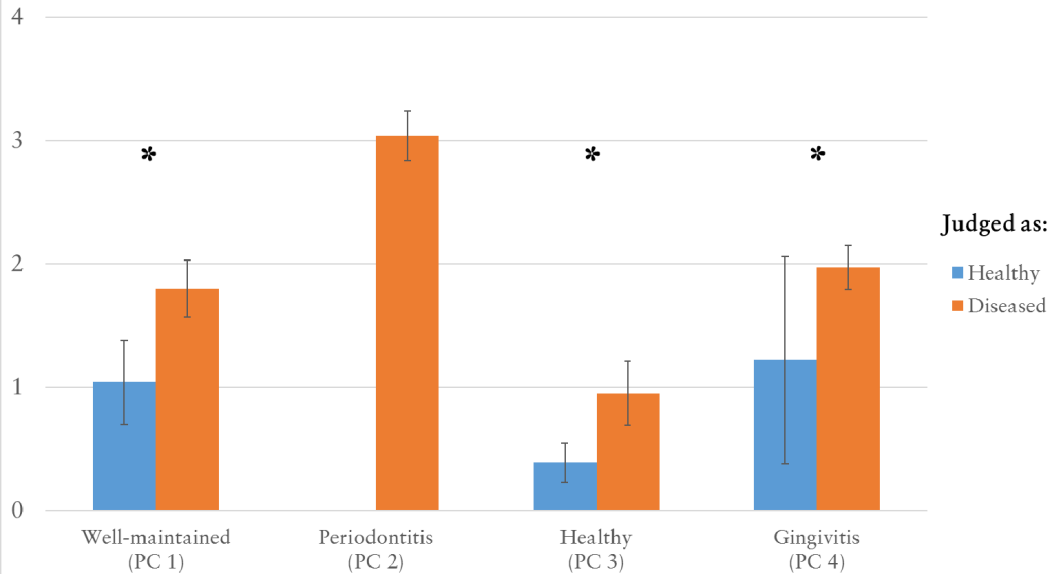

Figure 4. Mean number of treatment sessions for each patient case (PC) by general dentistry clinicians who judged the patient case either as healthy or diseased. ${ }^{*} p<0.05,95 \% \mathrm{Cl}$.

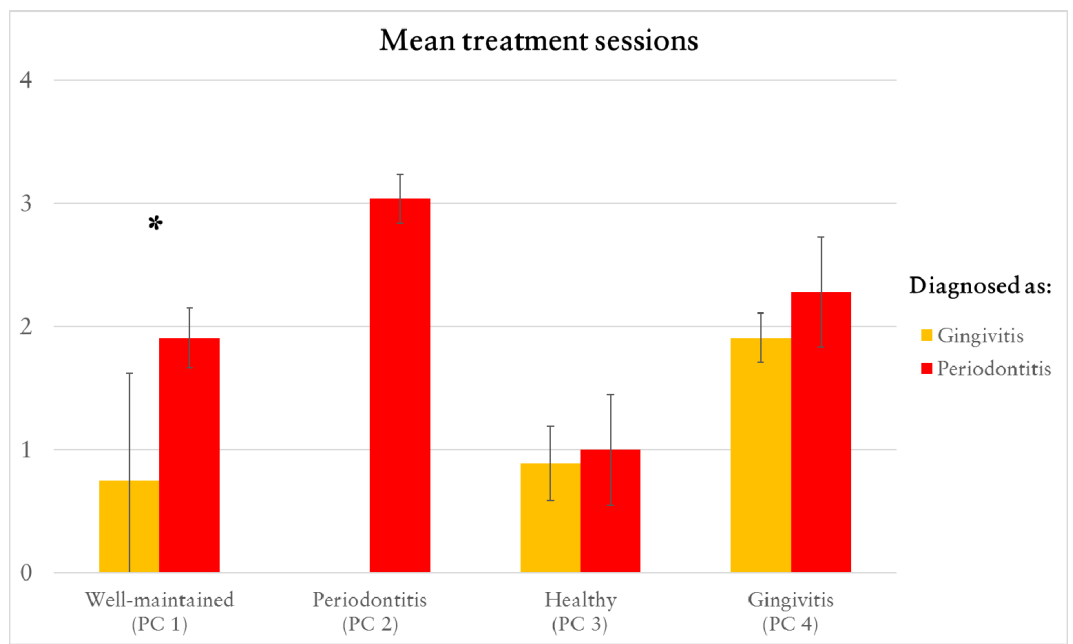

Figure 5. Mean number of treatment sessions for each patient case (PC) estimated by general dentistry clinicians who diagnosed the patient case with either gingivitis or periodontitis. ${ }^{*} p<0.05,95 \% \mathrm{Cl}$. 


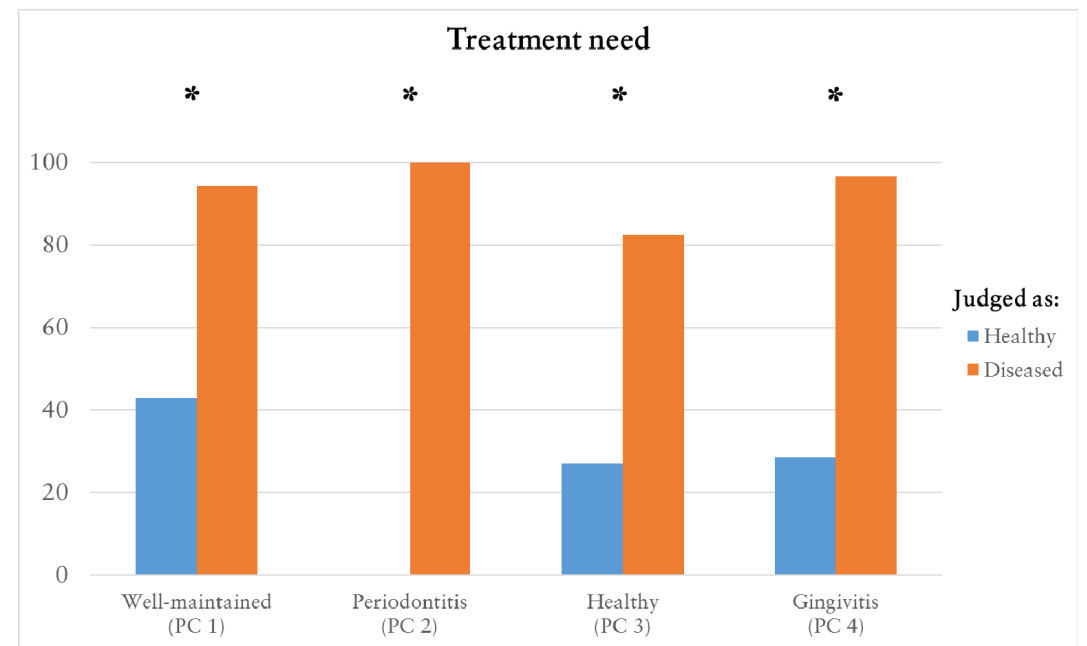

Figure 6. Percentage of periodontists who anticipated a treatment need after judging each patient case (PC) either as healthy or diseased. ${ }^{*} p<0.05$.

there were no differences in the healthy and gingivitis patient cases although diagnosed differently (Figure 5). Regarding periodontists, the anticipated treatment need was higher in the group of periodontists who judged the patient cases as diseased in comparison to those who judged the same patient cases as healthy (Figure 6).

\section{Treatment measures}

The most commonly recommended treatment measures in both the GDC (Table 6) and DS (Table 7) groups for all patient cases were disease information, oral hygiene instructions, polishing, scaling, and re-evaluation. The GDCs' suggested treatment measures were categorised into three categories: 1) instruction only, 2) instruction together with polishing, 3) scaling often combined with instructions. For GDCs in general, and when considering all the patient cases together, the most common combination of treatment measures were scaling $(93 \%)$ which was often combined with instruction $(31 \%)$. When comparing DSPs to DSMs, a significantly larger number of DSP recommended scaling and re-evaluation in three of the patient cases (except periodontitis patient case), 
Table 6. Percentage of general dentistry clinicians who proposed each treatment measure for each patient case (PC).

\begin{tabular}{lcccc} 
Treatment & \multicolumn{5}{c}{ Patient case } \\
measure & $\begin{array}{c}\text { Well-maintained } \\
(\text { PC 1) }\end{array}$ & $\begin{array}{c}\text { Periodontitis } \\
(\text { PC 2 })\end{array}$ & $\begin{array}{c}\text { Healthy } \\
(\text { PC 3) }\end{array}$ & $\begin{array}{c}\text { Gingivitis } \\
(\text { PC 4) }\end{array}$ \\
\hline Disease info. & 96.6 & 95.0 & 94.6 & 95.8 \\
\hline Oral hygiene instr. & 94.0 & 95.8 & 89.2 & 95.8 \\
\hline Polishing & 57.3 & 70.0 & 52.2 & 70.0 \\
\hline Scaling & 95.7 & 98.3 & 91.9 & 94.2 \\
\hline Re-evaluation & 67.5 & 92.5 & 30.6 & 67.5 \\
\hline Periodontal surg. & 3.4 & 10.8 & 1.8 & 0.8 \\
\hline
\end{tabular}

Table 7. Percentage of dental students who proposed each treatment measure for each patient case (PC). DSP: dental students from Paris, DSM: dental students from Malmö. ${ }^{*} p<0.05$.

\begin{tabular}{|c|c|c|c|c|c|c|c|c|}
\hline \multirow[b]{3}{*}{$\begin{array}{l}\text { Treatment } \\
\text { measure }\end{array}$} & \multicolumn{8}{|c|}{ Patient case } \\
\hline & \multicolumn{2}{|c|}{$\begin{array}{l}\text { Well-maintained } \\
\qquad(\text { PC 1) }\end{array}$} & \multicolumn{2}{|c|}{$\begin{array}{l}\text { Periodontitis } \\
\qquad \text { (PC 2) }\end{array}$} & \multicolumn{2}{|c|}{$\begin{array}{l}\text { Healthy } \\
\text { (PC 3) }\end{array}$} & \multicolumn{2}{|c|}{$\begin{array}{l}\text { Gingivitis } \\
\text { (PC 4) }\end{array}$} \\
\hline & $\begin{array}{c}\text { DSP } \\
\%\end{array}$ & $\begin{array}{c}\text { DSM } \\
\%\end{array}$ & $\begin{array}{c}\text { DSP } \\
\%\end{array}$ & $\begin{array}{c}\text { DSM } \\
\%\end{array}$ & $\begin{array}{c}\text { DSP } \\
\%\end{array}$ & $\begin{array}{c}\text { DSM } \\
\%\end{array}$ & $\begin{array}{c}\text { DSP } \\
\%\end{array}$ & $\begin{array}{c}\text { DSM } \\
\%\end{array}$ \\
\hline Disease info. & 96.3 & 97.2 & 98.8 & 100.0 & 91.0 & 81.8 & 98.8 & 94.4 \\
\hline Oral hygiene instr. & 100.0 & $88.9^{*}$ & 100.0 & 100.0 & 98.7 & 90.9 & 100.0 & 97.2 \\
\hline Polishing & 87.6 & $50.0^{*}$ & 88.9 & 77.8 & 93.6 & $54.5^{*}$ & 91.2 & 80.6 \\
\hline Scaling & 100.0 & $88.9^{*}$ & 98.7 & 97.2 & 97.4 & $78.8^{*}$ & 100.0 & $83.3 *$ \\
\hline Re-evaluation & 93.8 & $33.3 *$ & 100.0 & 94.4 & 66.7 & $18.2 *$ & 88.9 & $72.2 *$ \\
\hline Periodontal surg. & 2.5 & 0.0 & 32.1 & $8.6^{*}$ & 0.0 & 0.0 & 3.7 & 0.0 \\
\hline Local antibiotics & 1.2 & 0.0 & 3.7 & 0.0 & 0.0 & 0.0 & 1.2 & 0.0 \\
\hline Systemic antibiotics & 1.2 & 0.0 & 3.7 & 0.0 & 0.0 & 0.0 & 3.7 & 0.0 \\
\hline Other & 17.3 & $0.0^{*}$ & 19.8 & $0.0^{*}$ & 7.7 & 3.0 & 10.0 & 0.0 \\
\hline Root debridement & 14.9 & 0.0 & 19.8 & 0.0 & 6.5 & 0.0 & 10.0 & 0.0 \\
\hline Supp. Treatment & 1.2 & 0.0 & 0.0 & 0.0 & 0.0 & 3.0 & 0.0 & 0.0 \\
\hline Restraining & 1.2 & 0.0 & 0.0 & 0.0 & 0.0 & 0.0 & 0.0 & 0.0 \\
\hline $3^{\text {rd }}$ molar removal & 0.0 & 0.0 & 0.0 & 0.0 & 1.2 & 0.0 & 0.0 & 0.0 \\
\hline
\end{tabular}


polishing in the well-maintained and the healthy patient cases, oral hygiene instructions in the well-maintained patient case, periodontal surgery in the periodontitis patient case and other measures in the well-maintained and periodontitis patient cases (Table 7).

The periodontists on the other hand rated the importance of each treatment measure for each patient case. In terms of treatment measures, disease information and oral hygiene instructions were in general the most important ones, irrespective of the patient case, but they were considered as very important for the periodontitis and the gingivitis patient cases and somewhat less important for the two other patient cases. Polishing and periodontal surgery were considered as the least important treatment measures, while there was quite a variation regarding scaling, re-evaluation, and supportive therapy depending on the patient case. These treatment measures were most important for the periodontitis patient case and least important for the healthy patient case (Table 8).

Table 8. Mean (95\% confidence interval) visual analogue scale scores used to estimate importance of different treatment measures by periodontists ( $0=$ not important, $100=$ very important $)$ for each patient case (PC).

\begin{tabular}{lllll} 
Treatment & \multicolumn{4}{c}{ Patient case } \\
measure & \multicolumn{1}{c}{ Well-maintained } & Periodontitis & Healthy & \multicolumn{1}{c}{ Gingivitis } \\
\hline Disease info. & $66.5(56.2,76.8)$ & $86.8(81.8,91.8)$ & $55.9(43.2,68.6)$ & $78.2(70.9,85.5)$ \\
Oral hyg. instr. & $68.6(58.7,78.5)$ & $89.8(85.4,94.2)$ & $66.6(55.7,77.5)$ & $83.2(77.4,89.0)$ \\
\hline Polishing & $25.9(16.4,35.4)$ & $32.1(22.2,42.0)$ & $18.6(8.4,29.0)$ & $27.3(17.5,37.1)$ \\
Scaling & $60.8(51.5,70.1)$ & $84.6(78.8,90.4)$ & $46.7(35.5,57.9)$ & $53.5(43.9,63.1)$ \\
Re-evaluation & $53.1(41.5,64.7)$ & $84.4(78.1,90.7)$ & $33.5(19.8,47.2)$ & $56.4(46.5,66.3)$ \\
Perio. surg. & $0.4(-0.1,0.9)$ & $11.4(5.6,17.2)$ & $0.0(0.0)$ & $0.2(0.0,0.4)$ \\
Supp. treatment & $71.9(62.5,81.3)$ & $81.6(74.2,89.0)$ & $27.9(16.3,39.5)$ & $37.7(27.9,37.5)$ \\
\hline
\end{tabular}

\section{Treatment goals}

The GDCs' most frequent treatment goals, irrespective of the patient case, were to improve oral health awareness and thereby oral hygiene and to maintain periodontal status/prevent progression of 
the disease. The third and fourth most frequent goals were reduction of inflammation and PD, primarily in relation to the periodontitis and gingivitis patient cases, and to remove plaque and calculus (Table 9).

Table 9. Percentage of general dentistry clinicians who proposed each treatment goal for each patient case (PC). PD: probing depth.

\begin{tabular}{lcccc} 
Patient case & \multicolumn{4}{c}{ Treatment goals } \\
& $\begin{array}{l}\text { Improve oral } \\
\text { health } \\
\text { awareness }\end{array}$ & $\begin{array}{l}\text { Reduction of } \\
\text { inflammation } \\
\text { and PD }\end{array}$ & $\begin{array}{l}\text { Plaque and } \\
\text { calculus } \\
\text { removal }\end{array}$ & $\begin{array}{l}\text { Maintain } \\
\text { status/prevent } \\
\text { progression }\end{array}$ \\
\hline $\begin{array}{l}\text { Well-maintained } \\
\text { (PC 1) }\end{array}$ & 52.2 & 19.1 & 21.7 & 57.4 \\
$\begin{array}{l}\text { Periodontitis } \\
\text { (PC 2) }\end{array}$ & 52.1 & 39.3 & 28.2 & 57.3 \\
$\begin{array}{l}\text { Gingivitis } \\
\text { (PC 4) }\end{array}$ & 70.8 & 51.3 & 23.9 & 23.9 \\
\hline
\end{tabular}

\section{Prognostic assessment}

In all patient cases (healthy patient case excluded), the majority (60-95\%) of GDCs expected a worsening of the periodontal condition if no treatment was provided for ten years (Table 10). Considering the comparisons of the prognosis assigned to the different patient cases in relation to each other, most GDCs $(64 \%)$ made the same prognostic assessment in all three patient cases (i.e. anticipated worsening) while $27 \%$ deemed that the well-maintained and periodontitis patient cases had a worse prognosis than the gingivitis patient case. Periodontists prognostic assessment varied to some extent in all patient cases, but a majority expected a further progression of the disease in the well-maintained and periodontitis patient cases. However, the healthy and gingivitis patient cases were expected to retain their periodontal attachment level by the majority of periodontists (Table 10). Furthermore, a significantly higher number of periodontists who judged the patient cases as diseased (except the periodontitis patient case) expected progression of dis- 
ease in their prognostic assessment, compared with periodontists who judged the same patient cases as healthy (Table 11). Lastly, when comparing periodontists to the GDPs, a higher number of periodontists were more optimistic in their prognostic assessment than GDPs regarding the healthy and the gingivitis patient cases (Table 10).

Table 10. Percentage of each prognostic assessment for general dentistry clinicians (GDCs), general dental practitioners (GDPs) and periodontists in each patient case (PC). + Only GDCs who judged the patient cases as diseased were included (healthy patient case excluded). * Significant difference $(p<0.05$.) between GDPs and periodontists. W: well-maintained, P: periodontitis, H: healthy, G: gingivitis.

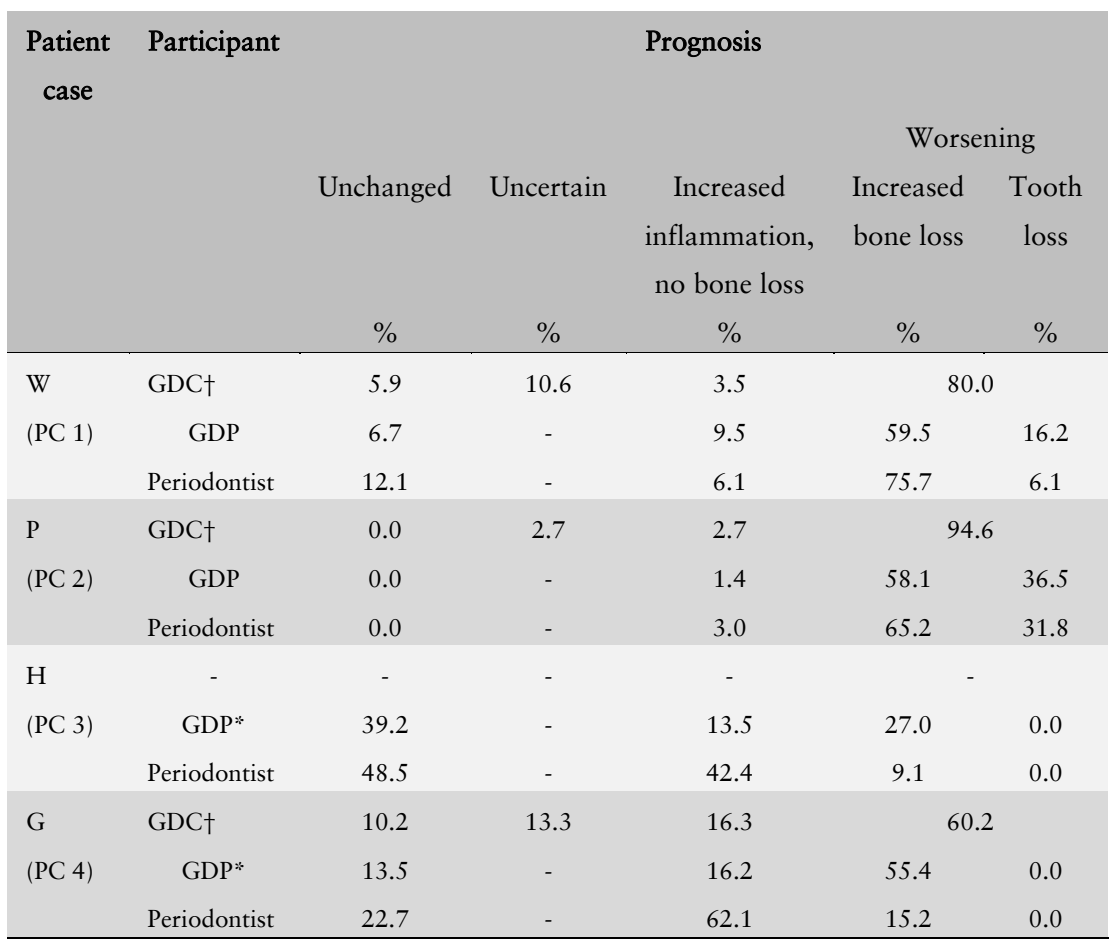


Table 11. Percentage of periodontists for each possible prognosis after judging each patient case (PC) either as healthy or diseased. $\mathrm{W}$ : well-maintained, $\mathrm{P}$ : periodontitis, $\mathrm{H}$ : healthy $\mathrm{G}$ : gingivitis. ${ }^{*} p$ $<0.05$.

\begin{tabular}{llcccc} 
Patient & Judgement & \multicolumn{2}{c}{ Prognosis } \\
case & & Unchanged & $\begin{array}{c}\text { Increased } \\
\text { inflammation, no } \\
\text { bone loss } \\
\text { Increased } \\
\text { bone loss }\end{array}$ & Tooth loss \\
& & $\%$ & $\%$ & $\%$ \\
\hline W & Healthy & 50.0 & 14.3 & 35.7 & 0.0 \\
(PC 1) & Diseased & 1.9 & 3.8 & 86.6 & 7.7 \\
P & Healthy & 0.0 & 0.0 & 100.0 & 0.0 \\
(PC 2) & Diseased & 0.0 & 3.1 & 64.6 & 32.3 \\
H & Healthy & 73.1 & 26.9 & 0.0 & 0.0 \\
(PC 3) & Diseased & 32.5 & 52.5 & 15.0 & 0.0 \\
G & Healthy & 100.0 & 0.0 & 0.0 & 0.0 \\
(PC 4) & Diseased $^{*}$ & 13.6 & 69.5 & 16.9 & 0.0 \\
\hline
\end{tabular}

When DSs were asked to assess the disease progression on a VAS, they anticipated a disease progression that included future loss of a tooth/teeth in the absence of treatment. The DSs of both dental schools anticipated the highest risk for the periodontitis patient case, followed by the well-maintained patient case. The gingivitis patient case was estimated to have moderate risk of progression while the healthy patient case was estimated to have the lowest risk. DSPs estimated a significantly higher risk for progression in the healthy and gingivitis patient cases in comparison to the risk estimated by DSMs (Figure 7). 


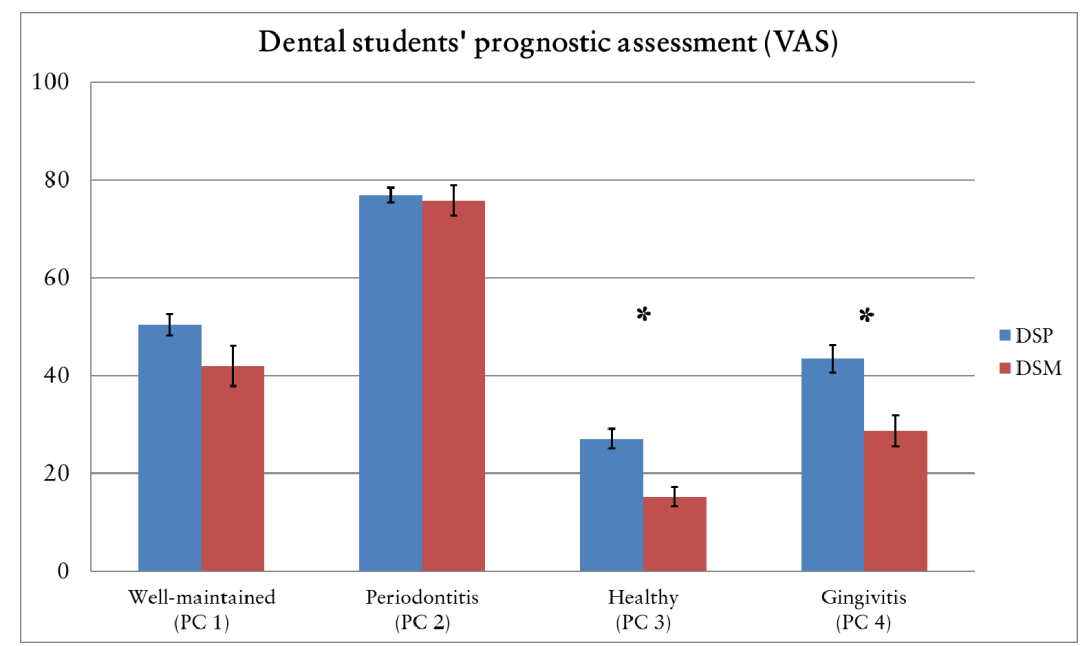

Figure 7. Dental students' average prognostic assessment for each patient case by means of a $100 \mathrm{~mm}$ visual analogue scale (VAS) $(95 \% \mathrm{Cl}) .0=$ no risk to lose tooth/teeth, $100=$ high risk to lose tooth/teeth. DSP: dental student from Paris, DSM: dental student from Malmö. * ${ }^{*}<0.05$.

\section{Qualitative data (Study V)}

The results consist of a general structure of the phenomenon "the lived experience of performing a periodontal treatment". This structure is based on a prior identification of the phenomenon's constituents (A-E), which were present in all three descriptions and should be considered as a coherent whole.

\section{The general structure}

The psychological meaning of the lived experience of performing a periodontal treatment in the context of general dentistry is characterised by an established treatment routine following a set pattern. The planning of the arrangement is defined by a requirement to base the treatment on the premises of the individual patient by attaining a holistic understanding. The extent of the entire treatment is based on the perception of deep periodontal pockets and their frequency whereas a single treatment session is instead influenced by the time available. In the situation where the phenomenon is 
experienced, patients are perceived as being partially aware of their oral condition and somewhat mindful of the demands placed on their oral hygiene. Patients' increased self-awareness is understood as an important factor in order to set up for the possibility of increased motivation for behavioural change in the direction of improving the patient's oral hygiene. The perception of patients' capacity to maintain a good oral hygiene is an integral part of the lived experience when conducting the periodontal treatment. The patients' oral hygiene capacity is perceived to be a crucial factor in obtaining successful results. Instructions in technique and choice of oral hygiene appliances is perceived as playing a pivotal role in the treatment process as is the patients' integration of instructions, techniques, and the use of appliances into their daily routines. The patients' integration of this self-care action is experienced as necessary in order to achieve an improved oral hygiene. The patients are perceived to adhere to the instructions and retain their motivation, but at the same time there is a sense of doubt that such positive behaviour would actually manifest itself in the patients' self-care process. Another fundamental characteristic of the phenomenon is the use of scaling that is considered successful although difficulties are experienced with regards to gaining visual and physical access to certain areas of the mouth. The combination of the use of ultrasonic and hand instruments is perceived as resulting in a thorough cleaning of the teeth surfaces. When carrying out the periodontal treatment, there is also an experience of a need to be supportive, in a professional way, of the patient.

\section{Constituent A: An established treatment routine}

The periodontal treatment is experienced as being an established and familiar routine. It is for the most part performed routinely and follows a set pattern. The planning of the whole treatment, in terms of number of treatment sessions, is experienced as being influenced by the frequency and magnitude of deep periodontal pockets but also as being based on information containing the patient's general health status, daily routines and oral hygiene routines. Moreover, several other factors, both patient related and organisation related, are perceived to be important when planning a 
single treatment session e.g. patient's susceptibility to the information intended to be given and the stress level of the patient as well as time consumption and time availability in the time schedule.

\section{Constituent B: Importance of oral hygiene}

Oral hygiene is experienced as an integral part of the periodontal treatment where the instructions related to a patients' self-care are perceived to be vital for the future results. Furthermore, it is experienced as important when the patient understands what impact the oral hygiene has on the periodontal disease and that it has to be successfully incorporated into the daily routines. Therefore, it is perceived as important that patients should also receive clear instruction in how and which oral hygiene appliances to use in order to avoid discontinuation. It is commonly perceived that patients progress in their self-care ability as they usually adhere to the given instructions and keep their motivation over time, even though this is not always readily apparent during the active treatment phase.

\section{Constituent C: Self-awareness and motivation of the patient} In the initial part of the periodontal treatment, the patients are experienced as self-aware with regards to their oral condition to a certain degree and partially aware of what is required of them in order to change their habits e.g. improving their oral hygiene or quit smoking. Furthermore, it is experienced as vital for patients to gain a better self-awareness of their own situation in order to become more motivated to change their habits.

\section{Constituent D: Support and doubt}

In relation to the phenomenon, it is experienced as important to be supportive of the patient during the periodontal treatment. However, a doubt towards the patient was also experienced. This was expressed as a doubt of the patient's adherence and compliance with oral hygiene instructions, e.g., a perceived uncertainty regarding whether or not the patient has understood the information given by the clinician or that patients indicated that they complied 
with the instructions while not showing any objective signs of this compliance.

Constituent E: Mechanical infection control

The mechanical infection control procedure is a fundamental part of the non-surgical treatment and often consists of scaling. This procedure is mostly experienced as being successful, both in its execution and when considering the obtained results following the completion of the procedure. However, it is also experienced that some areas in the oral cavity are more complicated to treat with regards to gaining good visual access and physical access with instruments. Regarding the instruments used during scaling, the ultrasonic and hand instruments were perceived to complement each other resulting in a more thorough cleaning of the teeth. 


\section{DISCUSSION}

\section{Main results}

Study I-IV, using a quantitative approach, showed that GDCs often vary in their judgement of a periodontal condition as being healthy or diseased. This in turn affected the proposed treatment. Although the GDCs varied in their treatment proposals for a single patient case, overall they proposed a similar treatment for patient cases with different periodontal conditions. This treatment includes, in most instances, the same treatment measures (disease information, oral hygiene instructions, scaling) and a similar amount of treatment. The periodontists also varied in their judgement which affected their subsequent treatment decisions, as it did for the GDCs. They also proposed a similar amount of treatment in three out of four patient cases (except the periodontitis patient case) but on the other hand they seem to have adapted the treatment measures to the individual patient cases. In contrast, the majority of DSs judged all patient cases as diseased but they, like the GDCs, proposed similar treatment to different patient cases. Furthermore, the prognostic assessment varied across the different groups of clinicians. The GDCs expected a deterioration of the periodontal status in most of the patient cases independently of their periodontal condition. DSs on the other hand anticipated a higher risk for the periodontitis patient case to lose his teeth while they made a similar prognostic assessment for the remaining patient cases. However, an individualised prognostic assessment was more apparent in the periodontist group since the majority made a different prognostic assessment 
for each patient case. This was in accordance with the patient cases' prevailing periodontal conditions.

Finally, some of the findings in study I-IV were confirmed in study $\mathrm{V}$, which used a qualitative approach. In this study, the results showed that the periodontal treatment is perceived, by DHs, as a standardised workflow. Furthermore, the patients' oral hygiene and self-awareness are perceived as important parameters as is the clinicians' supportive role of the patient.

\section{Judgement and diagnosis}

As results show, the clinicians do not agree, in most cases, as to whether or not a patient case is healthy or diseased. Therefore it is natural to interrogate this issue a bit further with the purpose to impose perhaps a putative explanation.

\section{What is a healthy periodontium?}

The first question to consider concerns the definition of health. In 1946 the member states of the WHO signed a constitution where it was acknowledged that every participating country should strive to promote and protect the health of every human being in the world (Grad, 2002). In the same document, health was partly defined as the absence of disease or infirmity. Similarly, one can note a clear but strict case definition of periodontal health, which requires a total lack of all signs and symptoms of periodontal disease, i.e., a pristine periodontium (Mariotti and Hefti, 2015). Looking back at the results, the greatest disagreement in judgement occurred in the healthy patient case (negligible bone loss and minimal signs of inflammation). The reason for this could be that some of the clinicians adhere to this strict definition of periodontal health, where some sites with occasional bleeding, although with normal attachment levels, will be considered as diseased. This is because the current clinical definition of gingivitis is based on site level, i.e. a site with BOP is diseased (Mariotti, 1999) and does not include a lower threshold on the patient level. Hence, a patient with a single bleeding site can, in principle, be diagnosed with gingivitis and will therefore be judged as diseased. However, other clinicians considered this patient case to be periodontally healthy which would in- 
dicate that this sharp division between health and disease does not make sense to them and is hence quite arbitrary (Papapanou and Susin, 2017). In turn, this might point to the fact that they add a subjective value in their judgement.

Furthermore, the clinicians disagreed, albeit to a less extent, in their judgement of the well-maintained patient case. Some clinicians considered this patient case as healthy although the patient case showed signs of past periodontitis experience in terms of a general attachment loss. The reason for their judgement could be that they perceive the disease as "cured" or successfully treated since there are no distinct signs showing disease activity and hence judge the patient case's periodontal condition as healthy. However, other clinicians might perceive the chronic element of periodontitis to be more important, since a chronic disease is associated with persistent and recurring health problems (Goodman et al., 2013), which could mean that it is seldom curable and therefore they judge the patient case as diseased.

To add more substance to this discussion one can also look at epidemiological studies and explore which case definitions are referred to when defining periodontal diseases. Some of the most commonly used definitions of periodontitis have been proposed by Centers for Disease Control and Prevention and the American Academy of Periodontology (CDC-AAP) (Eke et al., 2012) and European Federation of Periodontology (EFP) (Tonetti and Claffey, 2005). In their proposal one can see that different severity levels of periodontitis are clearly defined (Table 12) and mostly relating to attachment level, while definitions of periodontal health or gingivitis are not explicitly mentioned and in some instances fall into the category of "no periodontitis". However, other definitions of periodontal diseases in epidemiology have included healthy and gingivitis case definitions where the inflammation parameter in terms of bleeding is included (Hugoson et al., 2008). In the latter epidemiological study they have also employed a definition of health and disease in patient cases with past experience of periodontitis meaning that a patient with alveolar bone loss, but with a low number of bleeding sites and shallow PD, could be defined as healthy (Table 12). 


\section{Table 12. A summary of periodontal case definitions}

\begin{tabular}{|c|c|c|}
\hline CDC-AAP(Eke et al., 2012) & $\mathrm{EFP}$ (Tonetti and Claffey, 2005) & Hugosson et al., 2008 \\
\hline \multicolumn{3}{|c|}{ Definitions } \\
\hline $\begin{array}{l}\text { No periodontitis: } \\
\text { No evidence of mild, moder- } \\
\text { ate, or severe periodontitis }\end{array}$ & $\begin{array}{l}\text { Incipient periodontitis: } \\
\text { Presence of proximal at- } \\
\text { tachment loss of } \geq 3 \mathrm{~mm} \text { in } \\
\geq 2 \text { non-adjacent teeth. }\end{array}$ & $\begin{array}{l}\text { Group } 1 \text {. } \\
\text { Healthy or almost healthy } \\
\text { gingival units and normal } \\
\text { alveolar bone height; } \leq 12 \\
\text { bleeding gingival units in the } \\
\text { molar-pre-molar regions. }\end{array}$ \\
\hline $\begin{array}{l}\text { Mild periodontitis: } \\
\geq 2 \text { interproximal sites with } \\
\mathrm{AL} \geq 3 \mathrm{~mm} \text {, and } \geq 2 \text { inter- } \\
\text { proximal sites with } \mathrm{PD} \geq 4 \\
\mathrm{~mm} \text { (not on same tooth) or } \\
\text { one site with } \mathrm{PD} \geq 5 \mathrm{~mm}\end{array}$ & $\begin{array}{l}\text { Severe periodontitis: } \\
\text { Presence of proximal at- } \\
\text { tachment loss of } \geq 5 \mathrm{~mm} \text { in } \\
\geq 30 \% \text { of teeth present. }\end{array}$ & $\begin{array}{l}\text { Group } 2 \text {. } \\
\text { Gingivitis; }>12 \text { bleeding gin- } \\
\text { gival units in the molar-pre- } \\
\text { molar regions; normal alveo- } \\
\text { lar bone height. }\end{array}$ \\
\hline $\begin{array}{l}\text { Moderate periodontitis: } \\
\geq 2 \text { interproximal sites with } \\
\mathrm{AL} \geq 4 \mathrm{~mm} \text { (not on same } \\
\text { tooth), or } \geq 2 \text { interproximal } \\
\text { sites with } \mathrm{PD} \geq 5 \mathrm{~mm} \text { (not on } \\
\text { same tooth) }\end{array}$ & & $\begin{array}{l}\text { Group } 3 \text {. } \\
\text { Alveolar bone loss around } \\
\text { most teeth not exceeding } 1 / 3 \\
\text { of the length of the roots. }\end{array}$ \\
\hline \multirow[t]{2}{*}{$\begin{array}{l}\text { Severe periodontitis: } \\
\geq 2 \text { interproximal sites with } \\
\mathrm{AL} \geq 6 \mathrm{~mm} \text { (not on same } \\
\text { tooth) and } \geq 1 \text { interproximal } \\
\text { site with } \mathrm{PD} \geq 5 \mathrm{~mm}\end{array}$} & & $\begin{array}{l}\text { Group } 4 . \\
\text { Alveolar bone loss around } \\
\text { most teeth ranging between } \\
1 / 3 \text { and } 2 / 3 \text { of the length of } \\
\text { the roots. }\end{array}$ \\
\hline & & $\begin{array}{l}\text { Group } 5 \text {. } \\
\text { Alveolar bone loss around } \\
\text { most teeth exceeding } 2 / 3 \text { of } \\
\text { the length of the roots; pres- } \\
\text { ence of angular bony defects } \\
\text { and/or furcation defects. }\end{array}$ \\
\hline \multicolumn{3}{|c|}{ Comments } \\
\hline $\begin{array}{l}\text { Third molars excluded; total } \\
\text { periodontitis is defined as } \\
\text { the sum of mild, moderate, } \\
\text { and severe disease. } \\
\text { AL: Attachment loss } \\
\text { PD: Probing depth }\end{array}$ & $\begin{array}{l}\text { Periodontitis cannot be re- } \\
\text { flected by measurements of a } \\
\text { single variable. Past experi- } \\
\text { ence of periodontitis is re- } \\
\text { flected by attachment } \\
\text { loss/bone loss measurements. } \\
\text { Assessment of disease pres- } \\
\text { ence requires additional } \\
\text { measurement of bleeding on } \\
\text { probing and/or probing } \\
\text { pocket depth. }\end{array}$ & $\begin{array}{l}\text { Individuals in periodontal } \\
\text { disease Groups } 3,4 \text {, or } 5 \\
\text { were subdivided to differen- } \\
\text { tiate between those with } \\
\text { periodontal health and dis- } \\
\text { ease. The criteria for perio- } \\
\text { dontal health were } \leq 20 \% \\
\text { bleeding sites and } \leq 10 \% \\
\text { sites with probing pocket } \\
\text { depths } \geq 4 \text { mm. }\end{array}$ \\
\hline
\end{tabular}


Variation in judgement of patients' health conditions does not only occur in periodontology. Earlier studies have shown that physicians differ in their judgement of heart failure or hypertension as they either use different diagnostic information (Skånér et al., 2000) or even adhere to their own diagnostic criteria instead of those that have been formally agreed upon (Smith and Clayton, 1990). Furthermore, variation in periodontal judgement have also been reported in American (Martin et al., 2013) and Australian (Bailey et al., 2016) dental communities, where a single patient could be judged as either healthy or diagnosed with gingivitis or periodontitis by different clinicians. Hence, the variation in judgement seen in this thesis does not only apply to Swedish general dentistry, but is an international phenomenon. Therefore, it seems that there is a need to revise the definition of periodontal health in order to reach agreement, both in everyday clinical practice but also when considering case definitions applied in epidemiological studies. The lack of consensus on the case definition of periodontitis (Holtfreter et al., 2015) has previously been acknowledged and it is occasionally a challenge to distinguish between an active and inactive periodontitis site (Armitage, 2013). Therefore, it is important to reach an agreement when distinguishing between healthy and diseased periodontal condition since variation in judgement will inevitably influence the subsequent treatment decisions.

\section{Distinguishing between gingivitis and periodontitis}

A slight variation was also seen when comparing clinicians as to their given diagnosis. Patient cases with apparent bone loss (wellmaintained and periodontitis patient cases) were diagnosed with periodontitis by almost all clinicians. On the other hand, the DSPs deviated in their proposed diagnosis since a higher number of them proposed periodontitis in the patient cases with no apparent bone loss (healthy and gingivitis patient cases). This is somewhat surprising and could indicate that DSPs have a different knowledge base on periodontal disease, especially when compared to DSMs. Interestingly a substantial number of DSPs stated that they have received insufficient teaching in periodontology. On the other hand, 
diagnostic variations are common both within and between dental schools (Lane et al., 2015, John et al., 2013). Several factors could be held accountable for this variation. One of them is the differences in diagnostic judgement amongst clinical instructors (Lanning et al., 2005), which could have an impact on the students they teach. Another factor could be that students lack the appropriate criteria to interpret findings when diagnosing a state of disease (Maupomé and Sheiham, 1997).

\section{Periodontal treatment}

Treatment of most patients with periodontal diseases is often performed in a non-surgical fashion including measures aimed to successfully remove bacterial deposits and their sites of retention where an improvement of the patients' self-care is an essential factor (Sbordone et al., 1990). This together with enhancing the patients' motivation (Newton and Asimakopoulou, 2015) will ultimately lead to the goal of controlling the development of destructive periodontal diseases (Wennstrom et al., 1990).

\section{A standardised treatment - what does it mean?}

GDCs and DSs seem to recommend similar treatment, in terms of treatment measures and allocated treatment time, to most of the patients cases included in the questionnaire. This could indicate that they follow a "one-size-fits-all" approach in their treatment execution, which could result in overtreatment for some patient cases and undertreatment for others suggesting that resources are not being used optimally. Instead, the treatment should be individually tailored which means that all treatment measures should be adapted to each patient's periodontal status, especially measures which are meant to educate the patient in oral health standards. It has been shown that if an individually tailored oral health educational program is combined with scaling, a higher success rate of the non-surgical treatment is possible (Jönsson et al., 2010). Additionally, it carries a low incremental cost per treated patient (Jönsson et al., 2012). Findings indicating the presence of a standardised treatment approach are also reflected in the study conducted using a qualitative data collection method (study V) where a 
periodontal treatment was partly experienced as a routine task that follows a set pattern. The reason for this occurrence could be that the clinicians are indoctrinated to follow a certain path when carrying out the treatment, especially since the non-surgical periodontal treatment consists of similar measures, even for different patients. Furthermore, this finding might also capture the power of routines in the daily work of a clinical practitioner, especially since the phenomenon of the lived experience of conducting a periodontal treatment was constituted by an experience of working under time limits. A study on the influence of routines on people's estimation of time has shown that people who perform routine tasks are estimating the time to pass faster (Avni-Babad and Ritov, 2003). It is a bit farfetched to relate these outcomes to the findings in study $\mathrm{V}$ but speculatively it might indicate that if one perceives time to pass faster, then one could experience time limitations when performing an intended action, e.g., a treatment procedure. In turn this might pressure the clinician to prioritise some treatment measures over others, e.g., scaling instead of patient education (Liss et al., 2017), even though patient education is in most cases a very important part of the periodontal treatment.

In contrast, the periodontists seem to have a more individualised treatment approach, even though they also recommended similar treatment extent to different patient cases. On the other hand, the intention to treat varied from case to case and periodontists rated the variety of treatment measures to be of different importance for different patient cases, i.e., the importance was based on each patient case's periodontal condition. One might wonder why this approach is not implemented in general dentistry or undergraduate education, especially since the periodontists act as consultants and educators to the GDPs, DHs, and DSs. Influencing decision-making strategies or changing the practices of established clinicians is seldom an easy task but it has been shown that professional networks have a major influence on change (Watt et al., 2004) where the role of a persuasive expert could influence the clinicians to alter their decision-making strategies (Lee et al., 2016). Therefore, it is important for the periodontists to enhance their coherence regarding judgement and treatment decisions and convey and implement 
their way of reasoning more effectively to the sector of general dentistry.

\section{A plaque-free patient}

Scrutinising the recommended treatment measures further, one can see that both GDCs and DSs readily perform actions with the aim of eliminating plaque in the patient's mouth. They would provide disease information and oral hygiene instructions to all patient cases, even the patient cases with an initially excellent oral hygiene standard and few bleeding sites (well-maintained and healthy patient cases). Hence, inevitably their goal with the treatment is to have a plaque-free patient and eliminate all signs and symptoms of gingival inflammation, even though GDCs stated the opposite in their proposed treatment goals. The goal of a plaque free mouth is an unrealistic and unnecessary goal (Sheiham and Netuveli, 2002). Furthermore, if one tries hard to eliminate all signs of gingival inflammation in all patients it could possibly lead to overtreatment. This is because findings indicating inflammation (BOP) has a modest positive predictive value for progression of the disease (Lang, 1990). On the other hand, one has to acknowledge that the treatment measures proposed are very important in patients with general inflammation and plaque accumulation.

Looking back at the constituents that arose from the phenomenon investigated in study $\mathrm{V}$ it was acknowledged that the patients' oral hygiene routines are perceived as a vital component in the pur-

suit of positive results in the periodontal treatment. Additionally, the motivation to change a habit, e.g., improvement of the patient's self-care, is experienced to depend on the patient's self-awareness of his or her own situation. Changing a patient's habits is seldom easy but if the patient understands what measures needs to be taken to avoid tooth loss and understands the seriousness of the disease, they more often comply with instructions and incorporate the required oral hygiene measures in their daily routine (Karlsson et al., 2009, Newton and Asimakopoulou, 2015).

However, it was also apparent that a doubt from the clinicians' perspective, considering the patient's adherence to and compliance with oral hygiene instructions, was present in the experience of the 
phenomenon. This might indicate that the approach, which is readily used, is not always successful. The reason for this could be that the clinicians base their whole treatment plan exclusively on the patient's general health status and oral hygiene routines, as seen in constituent A of the phenomenon. This approach might not be that empowering for the patient since there are other patient-related factors to consider in one's treatment plan, e.g., establishment of goals set by the patients themselves (Jonsson et al., 2006). However, the clinicians are supportive of the patient which could in itself motivate the patient to improve their self-care or attain good health (Östergård et al., 2016).

\section{Learning environment impact on treatment decisions}

DSPs and DSMs varied significantly in their proposed treatment, regarding both treatment measures and treatment time. Variations in treatment decisions between students from different educational environments are common, both in the field of periodontology (Lane et al., 2015) and in other fields of dentistry, such as cariology (Bervian et al., 2009). Despite the common occurrence of these findings, it is still important to apprise these differences if one aims to strive for better coherence between DSs. Regarding the comparison between DSPs and DSMs there are several supposed explanations for the variation, one of them being differences in the amount of clinical training they receive. DSPs have less phantom training, start patient treatment later, and have fewer treatment hours in periodontology in comparison to DSMs. This could lead them to feel less confident in their treatment decisions and hence be more likely to propose several treatment measures and estimate a longer treatment time. Additionally, possible differences between the clinical instructors at the two dental schools in terms of approach as well as differences in treatment philosophies may influence the students' decision-making (Henzi et al., 2006, Cosyn and De Bruyn, 2007).

Although it is hard to delineate the precise reason for the observed variation in students' treatment decisions this could at least indicate that there might be a need for improved harmonisation in periodontal dental education in Europe. This could possibly be 
achieved if the ADEE and EFP consensus statements (Sanz and Meyle, 2010) are used as the point of departure when improving the curricula of the dental education.

\section{Prognostic assessment}

In general patient cases with varying signs of periodontal diseases, are expected to experience a further progression of their periodontal conditions in the absence of treatment. Therefore, it is important to find plausible explanations for this occurrence in order to understand why clinicians are, overall, pessimistic in their prognostic assessment.

\section{A pessimistic clinician}

In three of the patient cases (excluding the healthy patient case), GDCs are in general expecting the patient cases to deteriorate in absence of treatment. However, absence of treatment does not necessarily mean that a patient will experience a progressive attachment loss, even when having past experience of periodontitis (Lindhe et al., 1983). Focusing on each of the patient cases in particular one could agree that the periodontitis patient case would, obviously, experience a further attachment loss at some point in the absence of treatment (Lang and Tonetti, 2003). On the other hand, in the well-maintained patient case, a further deterioration of the periodontal status is not certain. Even though the patient case has past experience of periodontitis, in terms of bone loss, other clinical findings such as shallow pocket depths, an excellent oral hygiene and especially low frequency of bleeding sites indicate periodontal stability (Armitage, 1995, Lang et al., 1990, Lang et al., 1986). Despite this, even the majority of periodontists expected this patient case to experience further bone loss which could indicate that clinicians are probably basing their prognostic assessment on past periodontitis experience. Past experience of periodontitis is a strong risk predictor for disease progression (Bahrami et al., 2007) but since it is not a causative agent for periodontitis it cannot be considered as a risk factor (Pihlstrom, 2001a). However, it is common that clinicians base their prognostic assessment exclu- 
sively on signs representing overall severity of existing disease (Persson et al., 2003).

Interestingly, if one looks at the gingivitis patient case, again the majority of GDCs expected the patient case to develop periodontitis although the patient case had no obvious findings indicating attachment loss. This means that the GDCs probably based their assessment on signs indicating inflammation of the periodontal tissues i.e., BOP. This clinical finding is not a strong predictor for future attachment loss since not all gingivitis sites progress to periodontitis (Lang et al., 1986, Lang et al., 2009). On the other hand, one could also adhere to the notion that the onset of periodontitis may occur at a later stage in life (Schatzle et al., 2003b), but it still does not mean that the patient is susceptible to the disease. In contrast, only a small part of the periodontists expected the gingivitis patient case to develop periodontitis, which could be attributed to their proper, and expected, understanding of disease susceptibility.

Furthermore, DSs are similar to the GDCs in their prognostic assessment since they in general expect the well-maintained and the gingivitis patient cases to have the same risk of losing teeth in the future although, as mentioned before, the patient cases have clearly different grade of susceptibility to periodontitis. This could indicate that students are not completely aware of important risk factors for predicting progression of periodontal disease. The ability to predict progression is essential in improving their decision-making ability (Friesen et al., 2014)

The results point to a need to establish an improved line of reasoning with regards to risk and prognostic assessment, both among GDCs and DSs. This could be achieved if periodontists, with their proper understanding of the crucial risk and prognostic factors for periodontitis, share their knowledge with GDCs and DSs in a more effective manner.

\section{Judgement influencing the prognostic assessment}

It seems that the initial judgement of a patient case, as healthy or diseased, influences the subsequent prognostic assessment. The periodontists who judged a patient case as diseased are more prone to expect a worsening of the periodontal status than periodontists 
who judged the same patient case as healthy. Similarly, the difference between DSPs and DSMs in their prognostic assessment of the healthy and the gingivitis patient cases could be attributed to their differences in proposed diagnosis. This is since more DSP diagnosed these patient cases with periodontitis in comparison to DSM who were more reluctant to propose the same diagnosis. Once again, this shows the importance of establishing coherence in the judgement and diagnosis of a disease. This is particularly important since the prognostic assessment could influence the treatment decisions made (Lysell et al., 1993).

\section{Methodological considerations}

In studies (I-IV) performed using a quantitative data collection method there are some important considerations regarding representativeness of the sample and the patient cases. For the study (V) performed using a qualitative data collection method other issues are relevant which concern the validity and generalisability of the results.

\section{Representativeness of the sample and patient cases}

One of the reasons for choosing GDCs in the county of Halland as the sample population was that they corresponded to the general population of GDPs and DHs in the whole of Sweden when accounting for variables such as number of clinicians per inhabitant, gender distribution, and ratio between GDPs and DHs (The National Board of Health and Welfare, 2012).

The periodontists who filled out the questionnaire were also considered to be representative of the general population of periodontists in Sweden since they correspond to each other in gender and age distribution (The National Board of Health and Welfare, 2015). Regarding the sample of DSs, no claim is made that this corresponds to populations of DSs in other countries, especially since the aim of study III was to compare two different dental schools. This was done in order to find out if educational background influences clinicians' diagnostic judgements and treatment decisions in periodontology. 
The representativeness of the patient cases is equally important since this thesis deals with treatment strategies for patients who are frequent in a general dentistry setting. Therefore the patient cases represented the majority $(>85 \%)$ of middle-aged patients in a general dentistry practice (Hugoson et al., 2008). One could argue that four patient cases are too few to evaluate clinicians' diagnostic judgement and treatment decisions but increasing the number of patient cases and thus the number of the questions might affect the response rate negatively and lead to difficulties in collecting sufficient information (Lavrakas, 2008).

Regarding the response rate it is very important to reach as high response rate as possible. The response rate should fall in the proximity of $60 \%$ if one desires dependable results. However, if the response rate is lower than $60 \%$ a proper explanation is required as well as a comparison between the respondents and nonrespondents (Baruch, 1999). In the questionnaire, which was sent out to different populations separately, the response rate varied from $77-94 \%$ indicating a high response rate with no need to analyse the dropouts. There are several plausible explanations for the high response rate since the studies include respondents from different settings. Regarding the GDCs, the chief supervisor of the public dental service in the county of Halland acknowledged the importance of this particular study and encouraged the employees to respond by making time available for clinicians to complete the questionnaire. The DSs did not have incitement to fill out the questionnaire. Hence, it was important to make the questionnaire as slim as possible in order to encourage the students to complete it. The periodontists are in general more experienced in conducting and/or being a part of research projects. This could explain their willingness to be included in the study and a high number of them completed the questionnaire.

\section{Limitations}

In the decision-making process it is also important to relate to the patient's general status in terms of disease history, medications and habits (e.g., smoking) when proposing a diagnosis, presenting a treatment plan, or predicting disease progression (Page and Beck, 
1997). However, in the questionnaire studies, the intention was not to explore how the patients' general health status would influence the clinicians' treatment strategies. Instead these factors were eliminated in order to understand how patients with common periodontal conditions are judged and treated based on their clinical appearance. Moreover, other factors are equally important for the clinicians in their decision-making process, such as patients' preferences (Liedholm et al., 2000) and treatment cost (Grembowski et al., 1988). These factors have not been dealt with which could be considered as a limitation of the studies. On the other hand, if one needs to understand how one factor influences (e.g., a patient's periodontal condition) an outcome (e.g., treatment strategies), other factors need to be excluded in order to estimate the effect of the investigated factor.

For the patient cases in the questionnaire there were only radiographs from one single occasion. Therefore, the clinicians could not evaluate if a progression has occurred which could have caused the clinicians to be uncertain when judging and proposing diagnoses. Additionally, the radiologist's report stated that the patient cases with no obvious attachment loss (healthy and gingivitis patient cases) had negligible bone loss which could, in turn, have further influenced the clinicians' in their judgement and proposed diagnosis, especially if they would follow the statement slavishly. On the other hand, according to the fuzzy trace theory the clinicians rely on how they understand the given information (bottom-line meaning) and not on the facts they are presented with (Reyna, 2008) which explains why the majority did not diagnose these patient cases with periodontitis. Furthermore, "examining” virtual patients is not completely comparable to situations where a real examination is taking place. Virtual patients could be considered as real but a sense of prefabrication is often apparent (Bearman, 2003) which could be handled differently by different clinicians and contribute to variations.

\section{Validity and generalisability in DPPM}

One could be concerned about the validity and the generalisability of the results in study $\mathrm{V}$ since the data is obtained from few and 
carefully chosen individuals. One should be aware of the fact that this method is not using randomly selected participants. Instead, participants are purposely selected in order to acquire a rich and valid description of a situation where an individual has performed a periodontal treatment and not a description of the person experiencing the particular situation (Giorgi, 2009). Hence, it is important to acquire a true description of the desired situation and therefore the dental hygienists were chosen since they have affirmed experience of performing periodontal treatment. Another important factor for the validity is how the obtained descriptions are analysed since the researcher could potentially try to interpret the descriptions or even remove parts of it if they are regarded as unnecessary. This is not allowed by the method since all data is accounted for in the analysis. Additionally, phenomenological reduction is also applied which ensures that assumptions, earlier knowledge, and preconceptions about the phenomenon are bracketed which enables the researcher to reach valid results (Giorgi, 2009).

Regarding the generalisability one has to understand that it means something different to DPPM than it does to most studies performed with quantitative data collection methods where sampling method is crucial when generalising the results. In DPPM it is the results, not the participants, that are general. This means that the representativeness can only be ensured when the general structure of the phenomenon is disclosed which is not dependent on the participants experiencing the phenomenon (Englander, 2012). Therefore, the general structure of the phenomenon is built on rich descriptions, but in order to distinguish what constitutes the general structure one needs to isolate the bearing elements (constituents) of the phenomenon. By involving three participants with rich descriptions and using eidetic variations when analysing the description one can isolate the characteristics that are common to all descriptions and hence remove the characteristics of the phenomenon which are pertinent only to a single individual experiencing them (Englander, 2012). 


\section{CONCLUSION}

Patients with different periodontal conditions are treated in a similar way by general dental practitioners (GDPs), dental hygienists (DHs) and dental students (DSs). This could indicate that the treatment is performed in a standardised fashion and not individually tailored to each specific patient's treatment needs. Moreover, the majority of GDPs and DHs do not perform an individualised prognostic assessment since they expect that most patients will experience a worsening of their periodontal condition if left untreated, even patients without apparent susceptibility to periodontitis. The existence of an established treatment routine following a set pattern can be confirmed by DHs. They acknowledge important, patient-related factors when performing their treatment but they experience that an existing standardised workflow influences patient management. The findings from the studies included in this thesis could indicate that patients are receiving treatment unsuitable to their periodontal conditions, resulting in overtreatment for some patients and undertreatment for others, as well as a suboptimal use of resources. Additionally, GDPs, DHs, and periodontists seem to define periodontal health and disease differently, which ultimately affects subsequent treatment decisions and prognostic assessment of a single patient. Therefore, there is a need to clarify the definition of periodontal health and disease to improve the coherence in judgement. 


\section{FUTURE RESEARCH}

Several aspects of periodontal treatment have been addressed in this thesis; however, the patients' perspective remains unexplored. The patients' experience and involvement in the periodontal treatment is an important aspect to consider when evaluating how periodontal treatment is conducted in general dentistry. Therefore it would be valuable to study how patients experience the periodontal treatment they receive. This could be studied through a questionnaire or in a manner similar to study $\mathrm{V}$ by interviewing patients and analysing their descriptions using the descriptive phenomenological psychological method. The findings from such a study could be compared to the lived experience of performing a periodontal treatment and hence similarities and differences between the same experiences, seen from different perspectives, would be disclosed. The result could help us understand which factors are important for the patients when receiving periodontal treatment, which would facilitate clinicians achieving successful results. Furthermore, it could help dental care stakeholders when formulating guidelines for periodontal treatment since aspects relevant to the patients might reveal a different dimension to the treatment.

If future definitions of periodontal diseases can clarify the definition of health and disease one could, with a questionnaire similar to the one used in this thesis, evaluate if the new definitions have been successfully implemented. One also has to consider the fact that one does not know what the future holds and that the defini- 
tions of periodontal diseases, as we know them today, might cease to exist if potential biomarkers for the diseases were to be discovered. Anyway, it would be desirable to develop a diagnostic tool, which could accurately diagnose patients with gingivitis and periodontitis. This would eliminate the human error in diagnostic judgement and improve the coherence. Meanwhile, one should be mindful of the effect diagnostic judgement has on treatment decision. 


\section{ACKNOWLEDGMENTS}

I would like to express my sincere gratitude to all of you who have contributed in different ways to the finalisation of this thesis and supported me throughout the whole process. In particular I wish to thank:

Bengt Götrick, for your invaluable support throughout all of these years. You have been my mainstay and always available when I needed inspiration, expertise or just someone to talk to. I'm deeply thankful for your knowledge and experience that you have shared with me; it has been a pleasant journey.

Kerstin Knutsson, for introducing me to this project, for believing in me from the start and always challenged me to think outside the box. Your kindness, support and openness I will always cherish.

Andreas Stavropoulos, for all the opportunities you have given me to evolve in scientific research and in the field of periodontology. Your critical inputs have greatly broadened my horizons and your expertise has been immensely valuable.

Eva Wolf, for enlightening discussions about many aspects of qualitative data and your indisputable help in the realisation of my fifth study. I look forward to continue on the qualitative path together with you. 
Hadar Hallström, for your inspiring personality, which has made periodontology fun ever since my undergraduate studies. You have made a big imprint on me as a person and a clinician.

Kristina Bertl, for always being there for me in my clinical and research related quests and for all the fun and moments we have shared together. You are a true role model!

Magnus Englander, for introducing me to phenomenology and helping me learn many aspects of it. Thank you for always finding time for me in your busy schedule.

Henrik Jansson and Vianney Descroix, for co-authoring some of the studies in my thesis.

Lubna Alward, for being a true and everlasting friend ever since high school, throughout our undergraduate studies and now as colleagues. We have shared, and will share, many moments together.

Ayman Al-Okshi, for always being a good friend, listening to my concerns and sharing a lot of laughs.

Kristina Hellén-Halme and Mats Nilsson, for your openhearted support ever since I started with my PhD studies.

The entire staff of the Department of Oral Diagnostics, Oral and Maxillofacial Radiology and Department of Periodontology. It has been a pleasure working with all of you.

All of my undergraduate students who have always inspired me with your open minds and questioning attitude. You always light up my day.

The study participants who have made my research possible. 
My late grandparents, Tomislav and Jelica, who passed away during the writing of this thesis. You always made my summers enjoyable when visiting you and you will be deeply missed.

My in-laws, the Denic family, for showing interest in my work and always offering their kind support.

My brother Miodrag, his wife Danijela and their sons Boban and Predrag for just being who you are and always being there for me.

My father Bosko, for always highlighting the importance of education and believing in my success.

My mother Mila, for enduring all life's trials just to make it possible for me to have a decent upbringing, which has made me the man I am today. I am deeply thankful and respectful of your dedication.

And last, but definitely not least my loving wife Tatjana and my beloved son Nicolas, for making my life forever great, full of happiness and laughter. Tatjana, you have devoted yourself to me in a way that nobody else would. Your never-ending support has made everything that we share possible and there are no words that could express how much I love you.

This thesis has been supported by the Swedish Dental Society, Faculty of Odontology, Malmö University and Edit Agrells' foundation at the South Swedish Dental Society. 


\section{REFERENCES}

APPLEBAUM, M. 2012. Phenomenological psychological research as science. Journal of Phenomenological Psychology, 43, 36-72.

ARMITAGE, G. C. 1995. Clinical evaluation of periodontal diseases. Periodontol 2000, 7, 39-53.

ARMITAGE, G. C. 1999. Development of a classification system for periodontal diseases and conditions. Ann Periodontol, 4, 1-6.

ARMITAGE, G. C. 2002. Classifying periodontal diseases--a longstanding dilemma. Periodontol 2000, 30, 9-23.

ARMITAGE, G. C. 2004a. The complete periodontal examination. Periodontol 2000, 34, 22-33.

ARMITAGE, G. C. 2004b. Periodontal diagnoses and classification of periodontal diseases. Periodontol 2000, 34, 9-21.

ARMITAGE, G. C. 2013. Learned and unlearned concepts in periodontal diagnostics: a 50-year perspective. Periodontol 2000, 62, 20-36.

ARMITAGE, G. C. 2014. AAP centennial commentary: theme 3: Evolution and application of classification systems for periodontal diseases--a retrospective commentary*. J Periodontol, 85, 369-71.

AVNI-BABAD, D. \& RITOV, I. 2003. Routine and the perception of time. Journal of Experimental Psychology: General, 132, 543.

AXELSSON, P., NYSTRÖM, B. \& LINDHE, J. 2004. The long-term effect of a plaque control program on tooth mortality, caries and periodontal disease in adults. Journal of clinical periodontology, 31, 749-757.

BADERSTEN, A., NILVÉUS, R. \& EGELBERG, J. 1981. Effect of nonsurgical periodontal therapy. Journal of clinical periodontology, 8, 57-72. 
BAELUM, V. \& LOPEZ, R. 2003. Defining and classifying periodontitis: need for a paradigm shift? Eur J Oral Sci, 111, 2-6.

BAHRAMI, G., VAETH, M., ISIDOR, F. \& WENZEL, A. 2007. Marginal bone loss over 5 years in an adult Danish population. Oral Health Prev Dent, 5, 113-8.

BAILEY, D., BARROW, S. Y., CVETKOVIC, B., MUSOLINO, R., WISE, S., YUNG, C. \& DARBY, I. 2016. Periodontal diagnosis in private dental practice: a case-based survey. Australian dental journal, 61, 244-251.

BARABA, A., ANIĆ, I., DOMÉJEAN-ORLIAGUET, S., ESPELID, I. $\&$ B TVEIT, A. 2010. Survey of Croatian dentists' restorative treatment decisions on approximal caries lesions. Croatian medical journal, 51, 509-514.

BARUCH, Y. 1999. Response rate in academic studies-A comparative analysis. Human relations, 52, 421-438.

BEARMAN, M. 2003. Is virtual the same as real? Medical students' experiences of a virtual patient. Acad Med, 78, 538-45.

BECK, J. D. 1998. Risk revisited. Community Dent Oral Epidemiol, 26, 220-5.

BECKER, W., BECKER, B. E. \& BERG, L. E. 1984. Periodontal treatment without maintenance: a retrospective study in 44 patients. Journal of periodontology, 55, 505-509.

BERVIAN, J., TOVO, M. F., FELDENS, C. A., BRUSCO, L. C. \& ROSA, F. M. D. 2009. Evaluation of final-year dental students concerning therapeutic decision making for proximal caries. Brazilian oral research, 23, 54-60.

BIGRAS, B. R., JOHNSON, B. R., BEGOLE, E. A. \& WENCKUS, C. S. 2008. Differences in clinical decision making: a comparison between specialists and general dentists. Oral Surgery, Oral Medicine, Oral Pathology, Oral Radiology, and Endodontology, 106, 139-144.

CATON, J., GREENWELL, H., MAHANONDA, R., WILLIAMS, R., ZAPPA, U., CLAFFEY, N. M., A. \& ZACKIN, J. 1999. Consensus Report: Dental Plaque-Induced Gingival Diseases. Annals of Periodontology, 4, 18-19.

CHAPPLE, I. L., VAN DER WEIJDEN, F., DOERFER, C., HERRERA, D., SHAPIRA, L., POLAK, D., MADIANOS, P., LOUROPOULOU, A., MACHTEI, E. \& DONOS, N. 2015. Primary prevention of periodontitis: managing gingivitis. Journal of clinical periodontology, 42.

ÇIÇEK, E., ÖZSEZER-DEMIRYÜREK, E., ÖZEROL-KESKIN, N. B. \& MURAT, N. 2016. Comparison of treatment choices 
among endodontists, postgraduate students, undergraduate students and general dentists for endodontically treated teeth. International dental journal, 66, 201-207.

COBB, C. M. 2002. Clinical significance of non-surgical periodontal therapy: an evidence-based perspective of scaling and root planing. Journal of Clinical Periodontology, 29, 22-32.

COSYN, J. \& DE BRUYN, H. 2007. Interclinician disparity in periodontal decision making: need for consensus statements on surgical treatment. J Periodontal Res, 42, 311-7.

CRESWELL, J. W. 2009. Research design: Qualitative, quantitative, and mixed methods approaches, SAGE Publications, Incorporated.

DE SOUZA, P., DE TOLEDO, B., RAPP, G., ZUZA, E., NETO, C. \& MENDES, A. 2003. Reliability of bleeding and non-bleeding on probing to gingival histological features. Journal of the International Academy of Periodontology, 5, 71-76.

DENTINO, A., LEE, S., MAILHOT, J. \& HEFTI, A. F. 2013. Principles of periodontology. Periodontology 2000, 61, 16-53.

DOUGLASS, C. W. 2006. Risk assessment and management of periodontal disease. The Journal of the American Dental Association, 137, S27-S32.

EKE, P. I., PAGE, R. C., WEI, L., THORNTON-EVANS, G. \& GENCO, R. J. 2012. Update of the case definitions for population-based surveillance of periodontitis. J Periodontol, 83, $1449-54$.

ENGLANDER, M. 2012. The interview: Data collection in descriptive phenomenological human scientific research. Journal of Phenomenological Psychology, 43, 13-35.

ENGLANDER, M. 2016. The phenomenological method in qualitative psychology and psychiatry. International journal of qualitative studies on health and well-being, 11, 30682.

FAGGION, C. M., PETERSILKA, G., LANGE, D. E., GERSS, J. \& FLEMMIG, T. F. 2007. Prognostic model for tooth survival in patients treated for periodontitis. Journal of Clinical Periodontology, 34, 226-231.

FOWLER, C., GARRETT, S., CRIGGER, M. \& EGELBERG, J. 1982. Histologic probe position in treated and untreated human periodontal tissues. Journal of Clinical Periodontology, 9, 373-385.

FRIESEN, L. R., WALKER, M. P., KISLING, R. E., LIU, Y. \& WILLIAMS, K. B. 2014. Knowledge of risk factors and the periodontal disease-systemic link in dental students' clinical decisions. J Dent Educ, 78, 1244-51. 
FROSCH, D. L. \& KAPLAN, R. M. 1999. Shared decision making in clinical medicine: past research and future directions. American journal of preventive medicine, 17, 285-294.

GENCO, R. J. \& BORGNAKKE, W. S. 2013. Risk factors for periodontal disease. Periodontology 2000, 62, 59-94.

GIORGI, A. 1997. The theory, practice, and evaluation of the phenomenological method as a qualitative research procedure. Journal of phenomenological psychology, 28, 235-260.

GIORGI, A. 2005. The phenomenological movement and research in the human sciences. Nursing science quarterly, 18, 75-82.

GIORGI, A. 2009. The descriptive phenomenological method in psychology: A modified Husserlian approach, Duquesne University Press.

GOLD, S. I. 1995. Diagnostic techniques in periodontology: a historical review. Periodontology 2000, 7, 9-21.

GOODMAN, R. A., POSNER, S. F., HUANG, E. S., PAREKH, A. K. \& $\mathrm{KOH}, \mathrm{H} . \mathrm{K} .22013$. Defining and measuring chronic conditions: imperatives for research, policy, program, and practice. Prev Chronic Dis, 10, E66.

GOTFREDSEN, K. \& WALLS, A. W. 2007. What dentition assures oral function? Clinical Oral Implants Research, 18, 34-45.

GOTTLIEB, B. 1946. The new concept of periodontoclasia. Journal of Periodontology, 17, 7-23.

GRAD, F. P. 2002. The preamble of the constitution of the World Health Organization. Bulletin of the World Health Organization, 80, 981-984.

GREENSTEIN, G. 1984. The Role of Bleeding upon Probing in the Diagnosis of Periodontal Disease*: A Literature Review. Journal of periodontology, 55, 684-688.

GREENSTEIN, G. 2000. Nonsurgical periodontal therapy in 2000: a literature review. The Journal of the American Dental Association, 131, 1580-1592.

GREMBOWSKI, D., MILGROM, P. \& FISET, L. 1988. Factors influencing dental decision making. J Public Health Dent, 48, 159-67.

HAFFAJEE, A., SOCRANSKY, S., LINDHE, J., KENT, R., OKAMOTO, H. \& YONEYAMA, T. 1991. Clinical risk indicators for periodontal attachment loss. Journal of clinical periodontology, 18, 117-125.

HAUSMANN, E., ALLEN, K. \& CLEREHUGH, V. 1991. What alveolar crest level on a bite-wing radiograph represents bone loss? Journal of periodontology, 62, 570-572. 
HEITZ-MAYFIELD, L., TROMBELLI, L., HEITZ, F., NEEDLEMAN, I. \& MOLES, D. 2002. A systematic review of the effect of surgical debridement vs. non-surgical debridement for the treatment of chronic periodontitis. Journal of clinical periodontology, 29, 92-102.

HENZI, D., DAVIS, E., JASINEVICIUS, R. \& HENDRICSON, W. 2006. North American dental students' perspectives about their clinical education. J Dent Educ, 70, 361-77.

HOLTFRETER, B., ALBANDAR, J. M., DIETRICH, T., DYE, B. A., EATON, K. A., EKE, P. I., PAPAPANOU, P. N. \& KOCHER, T. 2015. Standards for reporting chronic periodontitis prevalence and severity in epidemiologic studies. Journal of clinical periodontology, 42, 407-412.

HUGOSON, A., SJÖDIN, B. \& NORDERYD, O. 2008. Trends over 30 years, 1973-2003, in the prevalence and severity of periodontal disease. Journal of clinical periodontology, 35, 405-414.

HUNINK, M. M., WEINSTEIN, M. C., WITTENBERG, E., DRUMMOND, M. F., PLISKIN, J. S., WONG, J. B. \& GLASZIOU, P. P. 2014. Decision making in health and medicine: integrating evidence and values, Cambridge University Press.

JEFFCOAT, M. K. \& REDDY, M. S. 2000. Advances in measurements of periodontal bone and attachment loss. Assessment of Oral Health. Karger Publishers.

JOHN, V., LEE, S.-J., PRAKASAM, S., ECKERT, G. J. \& MAUPOME, G. 2013. Consensus training: an effective tool to minimize variations in periodontal diagnosis and treatment planning among dental faculty and students. Journal of dental education, 77, 1022-1032.

JONSSON, B., LINDBERG, P., OSCARSON, N. \& OHRN, K. 2006. Improved compliance and self-care in patients with periodontitis--a randomized control trial. Int J Dent Hyg, 4, 77-83.

JÖNSSON, B., ÖHRN, K., LINDBERG, P. \& OSCARSON, N. 2010. Evaluation of an individually tailored oral health educational programme on periodontal health. Journal of clinical periodontology, 37, 912-919.

JÖNSSON, B., ÖHRN, K., LINDBERG, P. \& OSCARSON, N. 2012. Cost-effectiveness of an individually tailored oral health educational programme based on cognitive behavioural strategies in non-surgical periodontal treatment. Journal of clinical periodontology, 39, 659-665. 
JÖNSSON, B., ÖHRN, K., OSCARSON, N. \& LINDBERG, P. 2009. The effectiveness of an individually tailored oral health educational programme on oral hygiene behaviour in patients with periodontal disease: a blinded randomized-controlled clinical trial (one-year follow-up). Journal of clinical periodontology, 36, 1025-1034.

KARLSSON, E., LYMER, U. B. \& HAKEBERG, M. 2009. Periodontitis from the patient's perspective, a qualitative study. International journal of dental hygiene, 7, 23-30.

KAY, E. \& LOCKER, D. 1996. Variations in restorative treatment decisions: an international comparison. Community dentistry and oral epidemiology, 24, 376-379.

KAY, E. \& NUTTALL, N. 1995a. Clinical decision making--an art or a science? Part II: Making sense of treatment decisions. British dental journal, 178, 113-116.

KAY, E. \& NUTTALL, N. 1995b. Clinical decision making--an art or a science? Part III: To treat or not to treat? British dental journal, 178, 153-155.

KNUTSSON, K., LYSELL, L. \& ROHLIN, M. 2001. Dentists' decisions on prophylactic removal of mandibular third molars: a 10-year follow-up study. Community dentistry and oral epidemiology, 29, 308-314.

KNUTSSON, K., OHLSSON, B. \& TROEIN, M. 2005. Clinicians' management strategies for patients with dyspepsia: a qualitative approach. BMC gastroenterology, 5, 15.

KOSTOPOULOU, O., BRICKLEY, M., SHEPHERD, J. \& NEWCOMBE, R. 2000. Oral pathology: Perceived risk of future pathology associated with pathology-free third molars: a comparison of oral and maxillofacial surgeons and family dentists. British dental journal, 188, 28-31.

KWOK, V. \& CATON, J. G. 2007. Commentary: prognosis revisited: a system for assigning periodontal prognosis. Journal of periodontology, 78, 2063-2071.

LANE, B. A., LUEPKE, P., CHAVES, E., MAUPOME, G., ECKERT, G. J., BLANCHARD, S. \& JOHN, V. 2015. Assessment of the Calibration of Periodontal Diagnosis and Treatment Planning Among Dental Students at Three Dental Schools. Journal of dental education, 79, 16-24.

LANG, N., BARTOLD, P. M., CULLINAN, M., JEFFCOAT, M., MOMBELLI, A., MURAKAMI, S., PAGE, R., PAPAPANOU, P., TONETTI, M. \& DYKE, T. V. 1999. Consensus report: aggressive periodontitis. Annals of periodontology, 4, 53-53. 
LANG, N. P. 1990. Epidemiology of periodontal disease. Arch Oral Biol, 35 Suppl, 9s-14s.

LANG, N. P. 2014. Commentary: bacteria play a critical role in the etiology of periodontal disease. Journal of periodontology, 85, 211-213.

LANG, N. P., ADLER, R., JOSS, A. \& NYMAN, S. 1990. Absence of bleeding on probing an indicator of periodontal stability. Journal of clinical periodontology, 17, 714-721.

LANG, N. P., JOSS, A., ORSANIC, T., GUSBERTI, F. A. \& SIEGRIST, B. E. 1986. Bleeding on probing. A predictor for the progression of periodontal disease? Journal of clinical periodontology, 13, 590-596.

LANG, N. P., SCHATZLE, M. A. \& LOE, H. 2009. Gingivitis as a risk factor in periodontal disease. J Clin Periodontol, 36 Suppl 10, 3-8.

LANG, N. P. \& TONETTI, M. S. 2003. Periodontal risk assessment (PRA) for patients in supportive periodontal therapy (SPT). Oral Health Prev Dent, 1, 7-16.

LANNING, S. K., PELOK, S. D., WILLIAMS, B. C., RICHARDS, P. S., SARMENT, D. P., OH, T.-J. \& MCCAULEY, L. K. 2005. Variation in periodontal diagnosis and treatment planning among clinical instructors. Journal of Dental Education, 69, 325-337.

LAVRAKAS, P. J. 2008. Encyclopedia of survey research methods, Sage Publications.

LEE, J. S., LIM, H. C., KIM, M. S., CHOI, S. H. \& JUNG, U. W. 2016. Preferences and flexibility in decision-making among dental clinicians regarding the treatment of multirooted teeth: an interactive communication device-based survey at two academic conferences. J Periodontal Implant Sci, 46, 166-75.

LIEDHOLM, R., KNUTSSON, K., LYSELL, L., ROHLIN, M., BRICKLEY, M. \& SHEPHERD, J. P. 2000. The outcomes of mandibular third molar removal and non-removal: a study of patients' preferences using a multi-attribute method. Acta Odontol Scand, 58, 293-8.

LINDHE, J., HAFFAJEE, A. D. \& SOCRANSKY, S. S. 1983. Progression of periodontal disease in adult subjects in the absence of periodontal therapy. J Clin Periodontol, 10, 43342.

LINDHE, J., RANNEY, R., LAMSTER, I., CHARLES, A., CHUNG, C.-P., FLEMMIG, T., KINANE, D., LISTGARTEN, M., LÖE, H. \& SCHOOR, R. 1999. Consensus report: chronic periodontitis. Annals of Periodontology, 4, 38-38. 
LISS, A., ALIAN, A., WENNSTRÖM, J. \& ABRAHAMSSON, K. 2017. Professional competencies and work-related support in relation to periodontal therapy and work satisfaction: A questionnaire study among Swedish Dental Hygienists. International journal of dental hygiene.

LOE, H., THEILADE, E. \& JENSEN, S. B. 1965. EXPERIMENTAL GINGIVITIS IN MAN. J Periodontol, 36, 177-87.

LYSELL, L., BREHMER, B., KNUTSSON, K. \& ROHLIN, M. 1993. Judgement on removal of asymptomatic mandibular third molars: influence of the perceived likelihood of pathology. Dentomaxillofacial Radiology, 22, 173-177.

LÖE, H. 1993. Periodontal diseases: a brief historical perspective. Periodontology 2000, 2, 7-12.

LÖE, H., ANERUD, A., BOYSEN, H. \& MORRISON, E. 1986. Natural history of periodontal disease in man. Journal of clinical periodontology, 13, 431-440.

MARIOTTI, A. 1999. Dental plaque-induced gingival diseases. Ann Periodontol, 4, 7-19.

MARIOTTI, A. \& HEFTI, A. F. 2015. Defining periodontal health. BMC oral health, $15, \mathrm{~S} 6$.

MARTIN, J. A., GRILl, A. C., MATTHEWS, A. G., VENA, D., THOMPSON, V. P., CRAIG, R. G. \& CURRO, F. A. 2013. Periodontal diagnosis affected by variation in terminology. Journal of periodontology, 84, 606-613.

MAUPOMÉ, G. \& SHEIHAM, A. 1997. Decisions on diagnosis and management of approximal caries by final-year dental students. Dentomaxillofacial Radiology, 26, 107-111.

MCCAUL, L., MCHUGH, S. \& SAUNDERS, W. 2001. The influence of specialty training and experience on decision making in endodontic diagnosis and treatment planning. International endodontic journal, 34, 594-606.

MCGUIRE, M. K. \& NUNN, M. E. 1996. Prognosis versus actual outcome. II. The effectiveness of clinical parameters in developing an accurate prognosis. Journal of Periodontology, 67, 658-665.

MORSE, J. M. 1991. Approaches to qualitative-quantitative methodological triangulation. Nursing research, 40, 120-123.

NEWMAN, I. \& RIDENOUR, C. 1998. Qualitative-quantitative research methodology: Exploring the interactive continuum, SIU Press.

NEWTON, J. T. \& ASIMAKOPOULOU, K. 2015. Managing oral hygiene as a risk factor for periodontal disease: a systematic review of psychological approaches to behaviour change for 
improved plaque control in periodontal management. Journal of clinical periodontology, 42.

NIERI, M., MUZZI, L., CATTABRIGA, M., ROTUNDO, R., CAIRO, F. \& PRATO, G. P. P. 2002. The prognostic value of several periodontal factors measured as radiographic bone level variation: a 10-year retrospective multilevel analysis of treated and maintained periodontal patients. Journal of periodontology, 73, 1485-1493.

NYMAN, S., LINDHE, J. \& ROSLING, B. 1977. Periodontal surgery in plaque-infected dentitions. Journal of Clinical Periodontology, 4, 240-249.

ONWUEGBUZIE, A. J. \& LEECH, N. L. 2005. On becoming a pragmatic researcher: The importance of combining quantitative and qualitative research methodologies. International journal of social research methodology, 8, 375387.

ORBAN, B. 1942. Classification and Nomenclature of Periodontal Diseases*(1)(Based on Pathology, Etiology, and Clinical Picture). Journal of Periodontology, 13, 88-91.

OSHMAN, S., EL CHAAR, E., LEE, Y. N. \& ENGEBRETSON, S. 2016. Effect of patient age awareness on diagnostic agreement of chronic or aggressive periodontitis between clinicians; a pilot study. BMC oral health, 17, 27.

PAGE, R. C. \& BECK, J. D. 1997. Risk assessment for periodontal diseases. Int Dent J, 47, 61-87.

PAGE, R. C. \& SCHROEDER, H. E. 1976. Pathogenesis of inflammatory periodontal disease. A summary of current work. Laboratory investigation; a journal of technical methods and pathology, 34, 235-249.

PAPAPANOU, P. N. \& SUSIN, C. 2017. Periodontitis epidemiology: is periodontitis under-recognized, over-diagnosed, or both? Periodontol 2000, 75, 45-51.

PERSSON, R. G., ATTSTRÖM, R., LANG, N. P. \& PAGE, R. C. 2003. Perceived risk of deteriorating periodontal conditions. Journal of clinical periodontology, 30, 982-989.

PIHLSTROM, B. L. 2001a. Periodontal risk assessment, diagnosis and treatment planning. Periodontol 2000, 25, 37-58.

PIHLSTROM, B. L. 2001b. Periodontal risk assessment, diagnosis and treatment planning. Periodontology 2000, 25, 37-58.

POPE, C. \& MAYS, N. 1995. Reaching the parts other methods cannot reach: an introduction to qualitative methods in health and health services research. BMJ: British Medical Journal, 311,42 . 
RENVERT, S. \& PERSSON, G. 2002. A systematic review on the use of residual probing depth, bleeding on probing and furcation status following initial periodontal therapy to predict further attachment and tooth loss. Journal of clinical periodontology, 29, 82-89.

RENVERT, S. \& PERSSON, G. R. 2004. Supportive periodontal therapy. Periodontology 2000, 36, 179-195.

REYNA, V. F. 2008. A theory of medical decision making and health: fuzzy trace theory. Medical Decision Making, 28, 850-865.

SANZ, M. \& MEYLE, J. 2010. Scope, competences, learning outcomes and methods of periodontal education within the undergraduate dental curriculum: a consensus report of the 1st European Workshop on Periodontal Education--position paper 2 and consensus view 2. Eur J Dent Educ, 14 Suppl 1, 25-33.

SBORDONE, L., RAMAGLIA, L., GULLETTA, E. \& IACONO, V. 1990. Recolonization of the subgingival microflora after scaling and root planing in human periodontitis. Journal of Periodontology, 61, 579-584.

SCHATZLE, M., LOE, H., BURGIN, W., ANERUD, A., BOYSEN, H. \& LANG, N. P. 2003a. Clinical course of chronic periodontitis. I. Role of gingivitis. J Clin Periodontol, 30, 887 901.

SCHATZLE, M., LOE, H., LANG, N. P., HEITZ-MAYFIELD, L. J., BURGIN, W., ANERUD, A. \& BOYSEN, H. 2003b. Clinical course of chronic periodontitis. III. Patterns, variations and risks of attachment loss. J Clin Periodontol, 30, 909-18.

SECHREST, L. \& SIDANI, S. 1995. Quantitative and qualitative methods:: Is There an Alternative? Evaluation and program planning, 18, 77-87.

SHEIHAM, A. \& NETUVELI, G. S. 2002. Periodontal diseases in Europe. Periodontol 2000, 29, 104-21.

SKÅNÉR, Y., BRING, J., ULLMAN, B. \& STRENDER, L.-E. 2000. The use of clinical information in diagnosing chronic heart failure:: A comparison between general practitioners, cardiologists, and students. Journal of clinical epidemiology, 53, 1081-1088.

SMITH, T. \& CLAYTON, D. 1990. Individual variation between general practitioners in labelling of hypertension. BMJ, 300, 74-75.

SOCRANSKY, S. 1977. Microbiology of periodontal disease-present status and future considerations. Journal of periodontology, 48, 497-504. 
SORUM, P. C., STEWART, T. R., MULLET, E., GONZÁLEZVALLEJO, C., SHIM, J., CHASSEIGNE, G., SASTRE, M. T. M. \& GRENIER, B. 2002. Does choosing a treatment depend on making a diagnosis? US and French physicians' decision making about acute otitis media. Medical Decision Making, 22, 394-402.

STENMAN, J., HALLBERG, U., WENNSTRÖM, J. L. \& ABRAHAMSSON, K. H. 2009. Patients' attitudes towards oral health and experiences of periodontal treatment: a qualitative interview study. Oral health \& preventive dentistry, 7.

STEWART, K., GILL, P., CHADWICK, B. \& TREASURE, E. 2008. Qualitative research in dentistry. British dental journal, 204, 235-239.

SÄLZER, S., SLOT, D. E., VAN DER WEIJDEN, F. A. \& DÖRFER, C. E. 2015. Efficacy of inter-dental mechanical plaque control in managing gingivitis-a meta-review. Journal of clinical periodontology, 42.

THE NATIONAL BOARD OF HEALTH AND WELFARE 2012. Labour Supply in Sweden: Midwives, Nurses, Doctors, Dental Hygienists and Dentists 2010 (report in Swedish).

THE NATIONAL BOARD OF HEALTH AND WELFARE 2015. Labour Supply in Sweden: Midwives, Nurses, Physicians, Dental Hygienists and Dentists 2013 (report in Swedish).

TONETTI, M. S. \& CLAFFEY, N. 2005. Advances in the progression of periodontitis and proposal of definitions of a periodontitis case and disease progression for use in risk factor research. Group C consensus report of the 5th European Workshop in Periodontology. J Clin Periodontol, 32 Suppl 6, 210-3.

TUGNAIT, A., CLEREHUGH, V. \& HIRSCHMANN, P. 2000. The usefulness of radiographs in diagnosis and management of periodontal diseases: a review. Journal of dentistry, 28, 219226.

VAN DER WEIJDEN, F. A. \& SLOT, D. E. 2015. Efficacy of homecare regimens for mechanical plaque removal in managing gingivitis a meta review. Journal of clinical periodontology, 42.

WATT, R., MCGLONE, P., EVANS, D., BOULTON, S., JACOBS, J., GRAHAM, S., APPLETON, T., PERRY, S. \& SHEIHAM, A. 2004. The facilitating factors and barriers influencing change in dental practice in a sample of English general dental practitioners. Br Dent J, 197, 485-9; discussion 475. 
WENNSTROM, J. L., PAPAPANOU, P. N. \& GRONDAHL, K. 1990. A model for decision making regarding periodontal treatment needs. J Clin Periodontol, 17, 217-22.

WOLF, D. L. \& LAMSTER, I. B. 2011. Contemporary concepts in the diagnosis of periodontal disease. Dental Clinics of North America, 55, 47-61.

WULFF, H. R. \& GØTZSCHE, P. C. 2000. Den kliniska beslutsprocessen, Lund, Studentlitteratur.

ÅKESSON, L., HÅKANSSON, J. \& ROHLIN, M. 1992. Comparison of panoramic and intraoral radiography and pocket probing for the measurement of the marginal bone level. Journal of clinical periodontology, 19, 326-332.

ÖSTERGÅRD, G. B., ENGLANDER, M. \& AXTELIUS, B. 2016. A salutogenic patient-centred perspective of improved oral health behaviour-a descriptive phenomenological interview study. International journal of dental hygiene, 14, 142-150. 
APPENDIX 1 


\section{FALL 1}

Allmän anamnes:

Man, 48 år. Frisk. Ingen medicinering. Röker inte.

Lokal anamnes:

Ny patient. Bott utomlands i ca 10 år och fått regelbunden tandvård där.

Senaste undersökning och behandling för ca 1 år sedan.

Inga tandlagningar de senaste 15 åren.

\section{Status parodontalt:}

Supragingival tandsten: Underkäksfront och överkäks sexor.

För övriga fynd, se statuskort nedan:

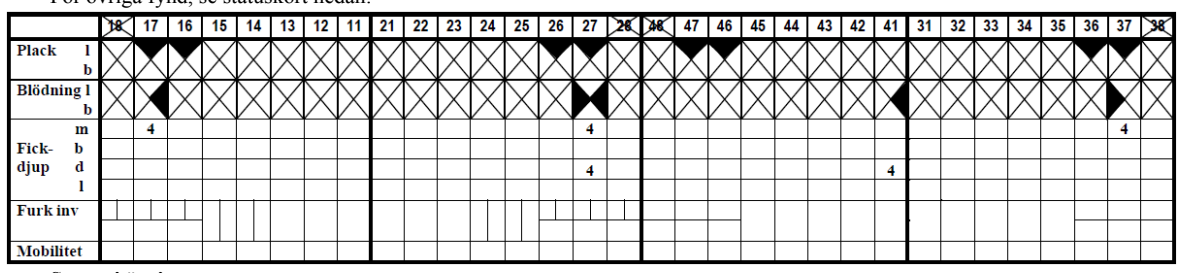

Status i övrigt:

Ua

Röntgenutlåtande:

Generellt ses marginal bennedbrytning som uppgår till ca $1 / 4$ - 1/3 av rotlängden.
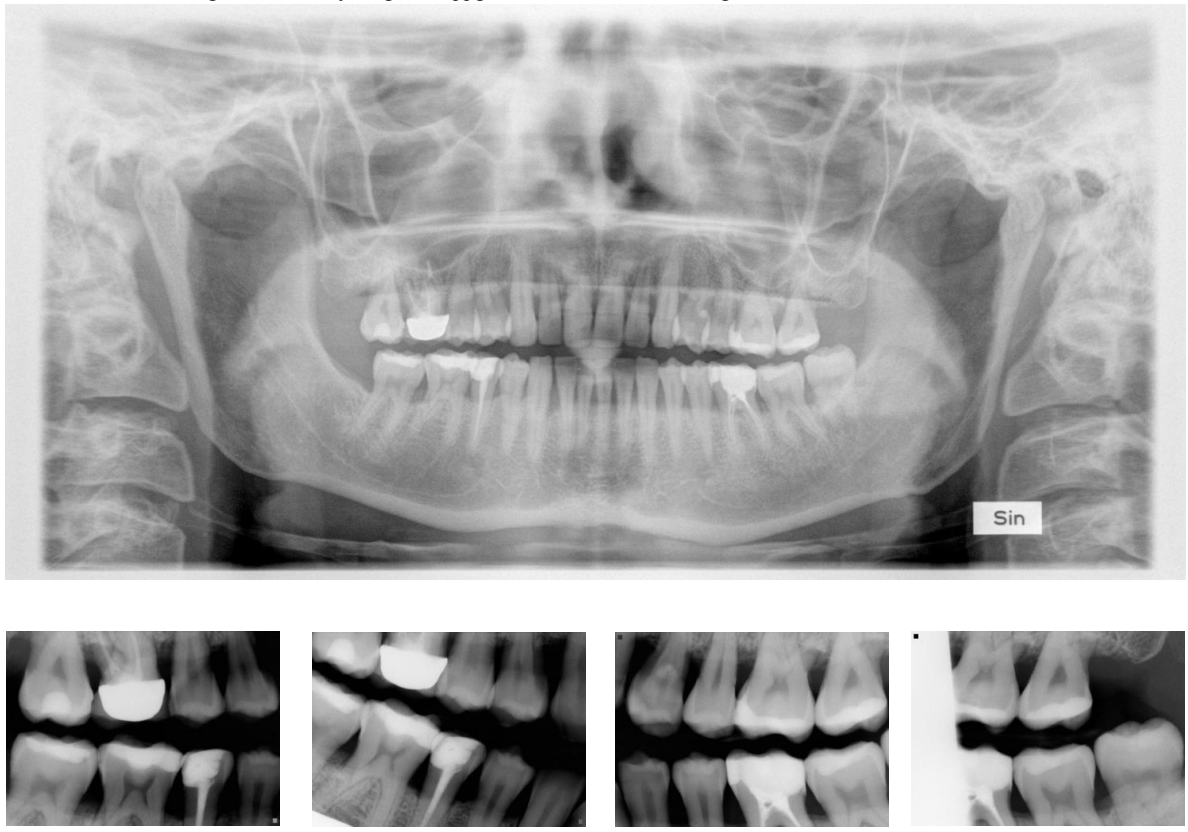


\section{FALL 2}

Allmän anamnes:

Man, 48 år. Frisk. Inga medicinering. Röker inte.

Lokal anamnes:

Ny patient. Bott utomlands i ca 10 år och fått regelbunden tandvård där.

Senaste undersökning och behandling för ca 1 år sedan.

Tänderna 26 och 46 extraherade p.g.a. trauma.

Inga tandlagningar de senaste 15 åren.

Status parodontalt:

Supragingival tandsten: Underkäksfront och överkäks sexor.

För övriga fynd, se statuskort nedan:

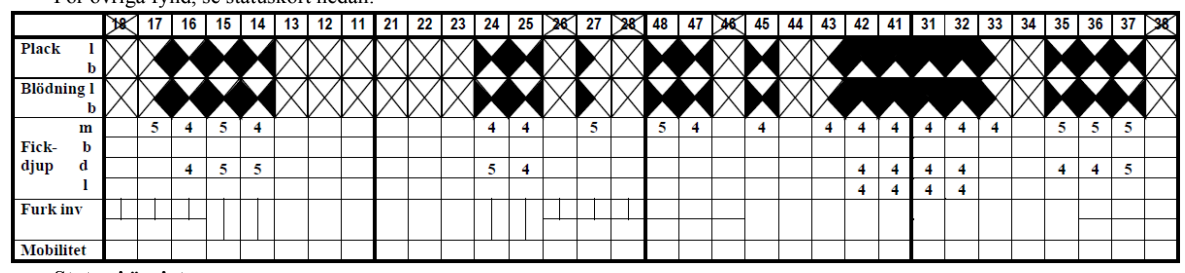

Status i övrigt:

$\mathrm{Ua}$

\section{Röntgenutlåtande:}

Generellt ses marginal bennedbrytning som uppgår till ca 1/4 - 1/3 av rotlängden.
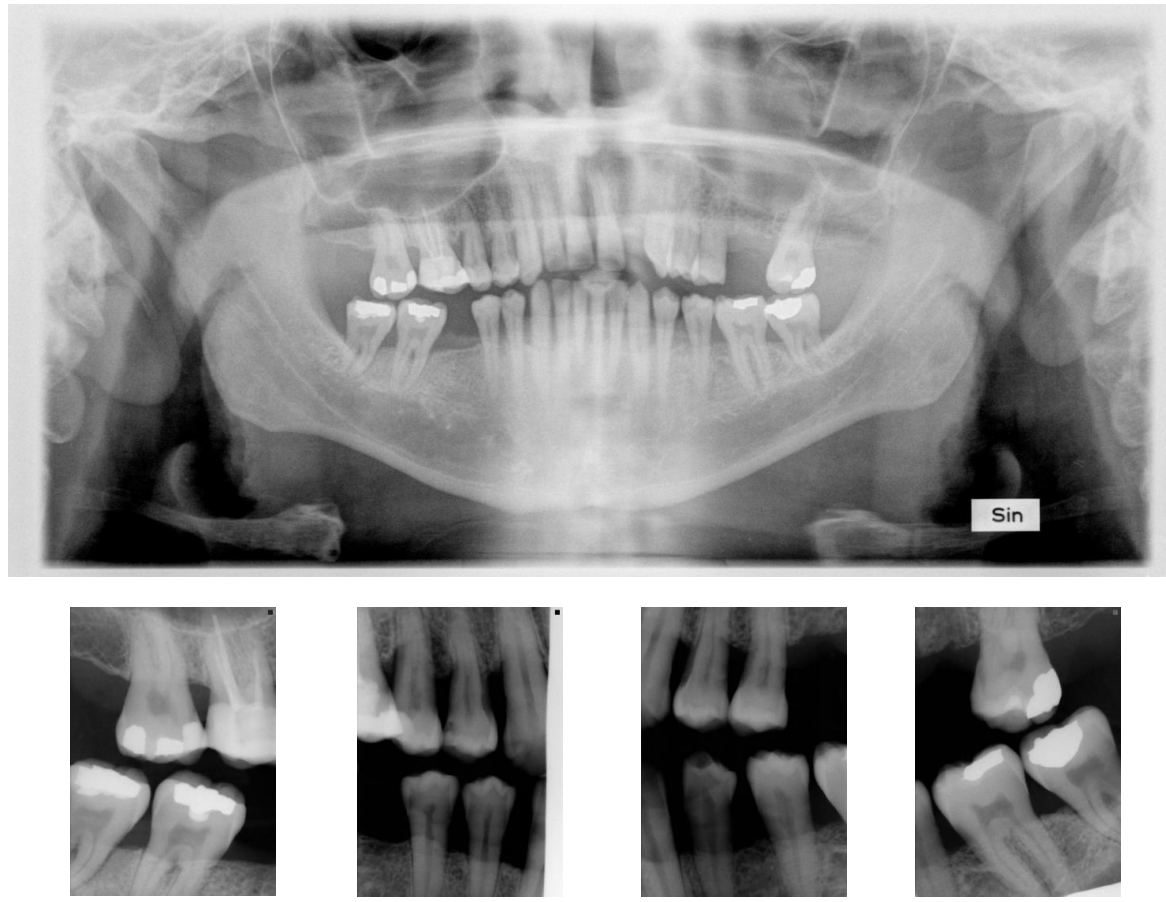


\section{FALL 3}

\section{Allmän anamnes:}

Man, 48 år. Frisk. Ingen medicinering. Röker inte.

Lokal anamnes:

Ny patient. Bott utomlands i ca 10 år och fătt regelbunden tandvård där.

Senaste undersökning och behandling för ca 1 år sedan.

11 rotfylld efter trauma.

Inga tandlagningar de senaste 15 åren.

\section{Status parodontalt:}

Supragingival tandsten: Underkäksfront och överkäks sexor.

För övriga fynd, se statuskort nedan:

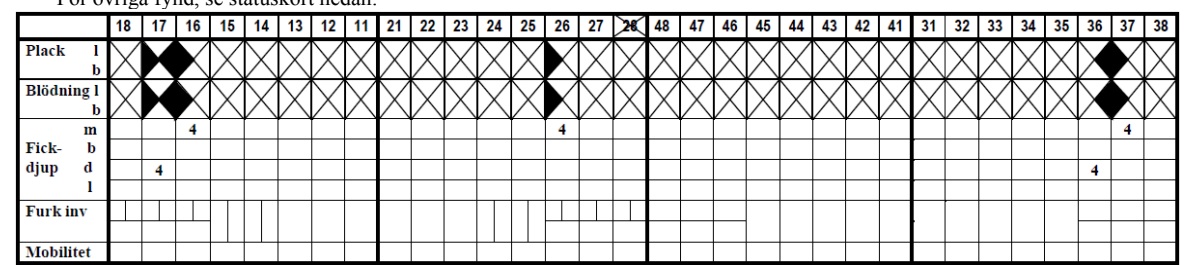

\section{Status i övrigt:}

Ua

\section{Röntgenutlåtande:}

Generellt ses ringa marginal bennedbrytning.
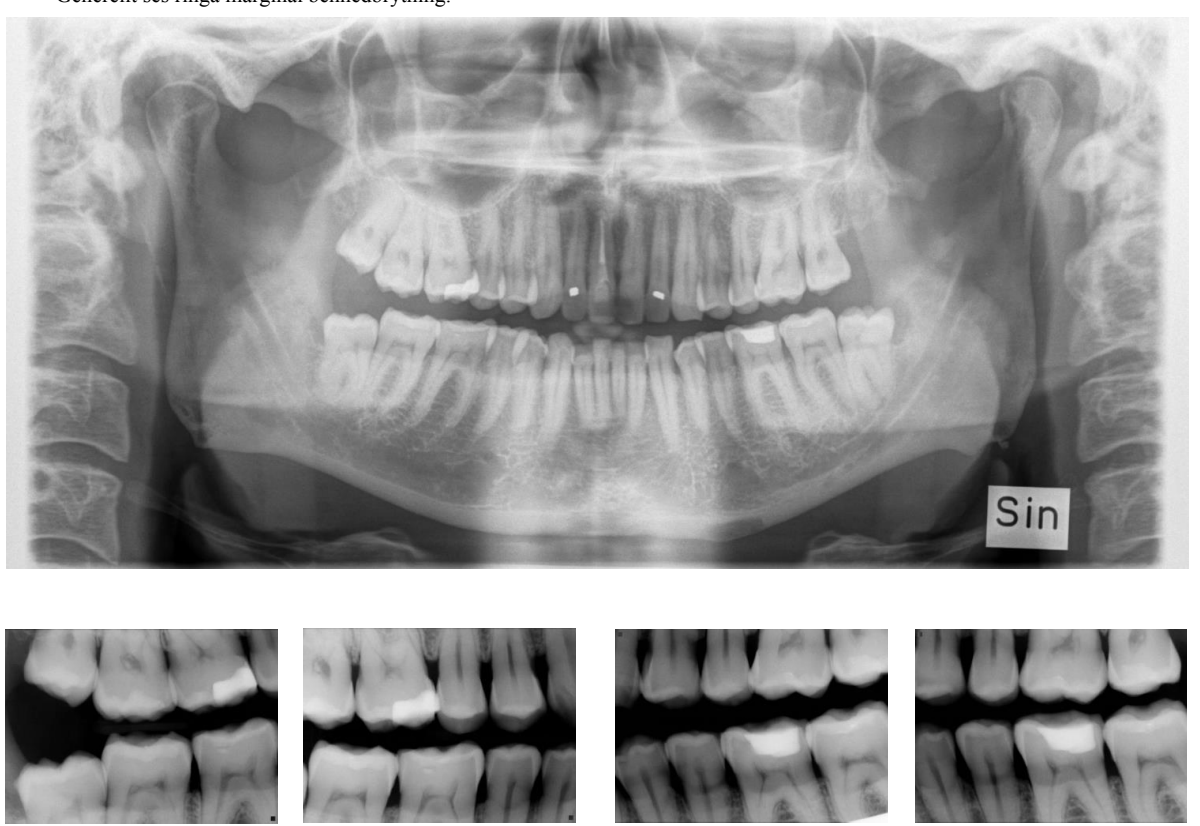
FALL 4

Allmän anamnes:

Man, 48 år. Frisk. Ingen medicinering. Röker inte.

\section{Lokal anamnes:}

Ny patient. Bott utomlands i ca 10 år och fått regelbunden tandvård där.

Senaste undersökning och behandling för ca 1 år sedan.

Tandreglerad tidigare.

Inga tandlagningar de senaste 15 åren.

\section{Status parodontalt:}

Supragingival tandsten: Underkäksfront och överkäks sexor.

För övriga fynd, se statuskort nedan:

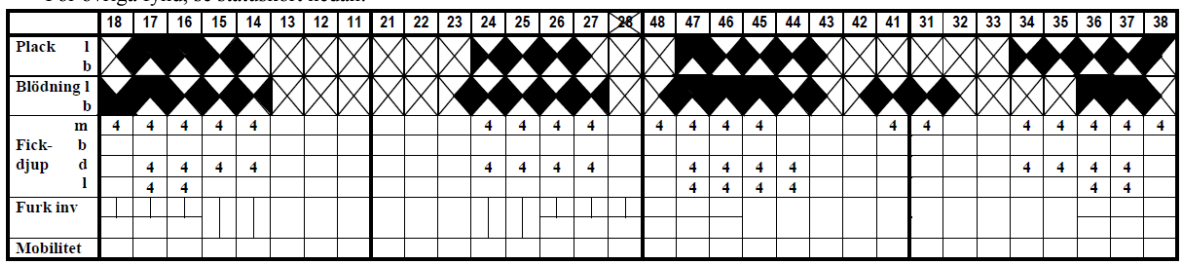

Status i övrigt:

$\mathrm{Ua}$

Röntgenutlåtande:

Generellt ses ringa marginal bennedbrytning.
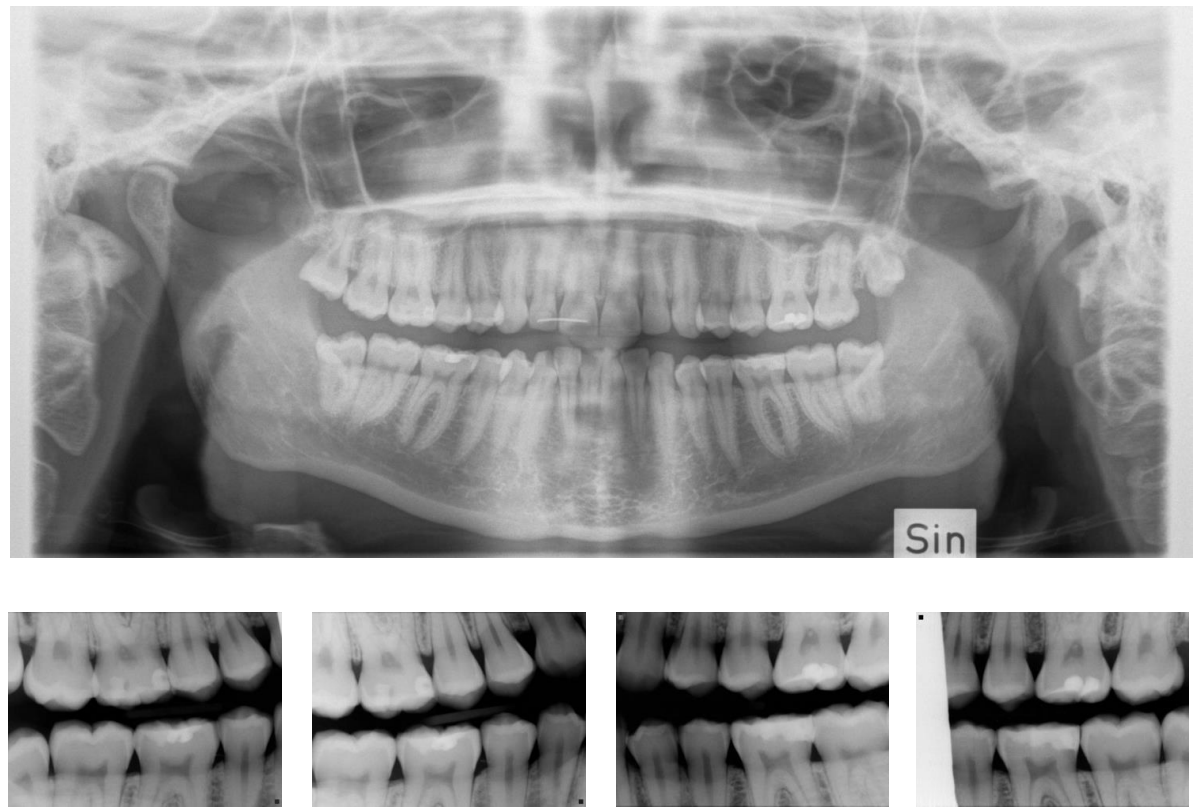



ISBN 978-9I-7 IO4-906-3 (print)

ISBN 978-9I-7 IO4-907-O (pdf)

MALMÖ UNIVERSITY 20506 MALMÖ, SWEDEN WWW.MAU.SE 